\title{
Ab Initio and Density Functional Theory Reinvestigation of Gas-Phase Sulfuric Acid Monohydrate and Ammonium Hydrogen Sulfate
}

\author{
Theo Kurtén,*,† Markku R. Sundberg, ${ }^{\ddagger}$ Hanna Vehkamäki, ${ }^{\dagger}$ Madis Noppel, ${ }^{\S}$ \\ Johanna Blomqvist, ${ }^{\#}$ and Markku Kulmala ${ }^{\dagger}$ \\ Department of Physical Sciences, University of Helsinki, P.O. Box 64, FIN-00014 University of Helsinki, \\ Finland, Laboratory of Inorganic Chemistry, Department of Chemistry, University of Helsinki, P.O. Box 55, \\ FIN-00014 University of Helsinki, Finland, Institute of Environmental Physics, University of Tartu, \\ 18 Ülikooli Str., 50090 Tartu, Estonia, and CSC-Scientific Computing Ltd., P.O. Box 405 (Keilaranta 14), \\ FIN-02101 Espoo, Finland
}

Received: March 2, 2006; In Final Form: April 10, 2006

\begin{abstract}
We have calculated the thermochemical parameters for the reactions $\mathrm{H}_{2} \mathrm{SO}_{4}+\mathrm{H}_{2} \mathrm{O} \leftrightarrow \mathrm{H}_{2} \mathrm{SO}_{4} \cdot \mathrm{H}_{2} \mathrm{O}$ and $\mathrm{H}_{2}-$ $\mathrm{SO}_{4}+\mathrm{NH}_{3} \leftrightarrow \mathrm{H}_{2} \mathrm{SO}_{4} \cdot \mathrm{NH}_{3}$ using the B3LYP and PW91 functionals, MP2 perturbation theory and four different basis sets. Different methods and basis sets yield very different results with respect to, for example, the reaction free energies. A large part, but not all, of these differences are caused by basis set superposition error (BSSE), which is on the order of $1-3 \mathrm{kcal} \mathrm{mol}^{-1}$ for most method/basis set combinations used in previous studies. Complete basis set extrapolation (CBS) calculations using the cc-pV(X+d)Z and aug-cc$\mathrm{pV}(\mathrm{X}+\mathrm{d}) \mathrm{Z}$ basis sets (with $\mathrm{X}=\mathrm{D}, \mathrm{T}, \mathrm{Q}$ ) at the B3LYP level indicate that if BSSE errors of less than 0.2 $\mathrm{kcal} \mathrm{mol}^{-1}$ are desired in uncorrected calculations, basis sets of at least aug-cc-pV(T+d)Z quality should be used. The use of additional augmented basis functions is also shown to be important, as the BSSE error is significant for the nonaugmented basis sets even at the quadruple- $\zeta$ level. The effect of anharmonic corrections to the zero-point energies and thermal contributions to the free energy are shown to be around $0.4 \mathrm{kcal}^{\mathrm{mol}}{ }^{-1}$ for the $\mathrm{H}_{2} \mathrm{SO}_{4} \cdot \mathrm{H}_{2} \mathrm{O}$ cluster at $298 \mathrm{~K}$. Single-point CCSD(T) calculations for the $\mathrm{H}_{2} \mathrm{SO}_{4} \cdot \mathrm{H}_{2} \mathrm{O}$ cluster also indicate that B3LYP and MP2 calculations reproduce the CCSD(T) energies well, whereas the PW91 results are significantly overbinding. However, basis-set limit extrapolations at the CCSD(T) level indicate that the B3LYP binding energies are too low by ca. $1-2 \mathrm{kcal} / \mathrm{mol}$. This probably explains the difference of about 2 $\mathrm{kcal} \mathrm{mol}^{-1}$ for the free energy of the $\mathrm{H}_{2} \mathrm{SO}_{4}+\mathrm{H}_{2} \mathrm{O} \leftrightarrow \mathrm{H}_{2} \mathrm{SO}_{4} \cdot \mathrm{H}_{2} \mathrm{O}$ reaction between the counterpoise-corrected B3LYP calculations with large basis sets and the diffusion-based experimental values of S. M. Ball, D. R. Hanson, F. L Eisele and P. H. McMurry (J. Phys. Chem. A. 2000, 104, 1715). Topological analysis of the electronic charge density based on the quantum theory of atoms in molecules (QTAIM) shows that different method/basis set combinations lead to qualitatively different bonding patterns for the $\mathrm{H}_{2} \mathrm{SO}_{4} \cdot \mathrm{NH}_{3}$ cluster. Using QTAIM analysis, we have also defined a proton transfer degree parameter which may be useful in further studies.
\end{abstract}

\section{Introduction}

In atmospheric conditions, new particle formation is thought to involve sulfuric acid and water molecules, with possible contributions from ammonia or some organic species. ${ }^{1,2}$ To obtain structural and thermochemical parameters for, e.g., nucleation simulations, ab initio and density functional theory calculations have been carried out on sulfuric acid hydrates ${ }^{3-7}$ and sulfuric acid-ammonia-water clusters. ${ }^{8}{ }^{9}$ However, the results obtained in different studies vary strongly. To understand the discrepancies between earlier studies, and to facilitate further, more reliable atmospheric calculations, we have carried out a systematic analysis of the effects of the computational method and the basis set on the geometrical, thermochemical and bonding topological properties of sulfuric acid monohydrate and ammonium hydrogen sulfate clusters.

\footnotetext{
* Corresponding author. E-mail: theo.kurten@helsinki.fi

Department of Physical Sciences, University of Helsinki.

Department of Chemistry, University of Helsinki.

$\S$ University of Tartu.

\# CSC - Scientific Computing Ltd..
}

\section{Previous Results}

Bandy and Ianni ${ }^{4}$ calculated the free energy of the reaction $\mathrm{H}_{2} \mathrm{SO}_{4}+\mathrm{H}_{2} \mathrm{O} \leftrightarrow \mathrm{H}_{2} \mathrm{SO}_{4} \cdot \mathrm{H}_{2} \mathrm{O}$ to be $-0.6 \mathrm{kcal} \mathrm{mol}^{-1}$ (at $298 \mathrm{~K}$ and $1 \mathrm{~atm})$ at the B3LYP/6-311++G(2d,2p) level, whereas Re et al. ${ }^{5}$ gave values of -4.3 and $-2.4 \mathrm{kcal} \mathrm{mol}^{-1}$ at the B3LYP/ D95(d,p) and B3LYP/D95++(d,p) levels, respectively. (We have chosen to report all energies in $\mathrm{kcal} \mathrm{mol}^{-1}$, as most earlier studies use this unit. $1 \mathrm{kcal} \mathrm{mol}^{-1}=4.184 \mathrm{~kJ} \mathrm{~mol}^{-1}$.) The PW91/DNP computations of Ding et al. ${ }^{6}$ are in agreement with Re's results, yielding a value of $-2.5 \mathrm{kcal} \mathrm{mol}^{-1}$, but Al Natsheh et $\mathrm{al}^{7}$ recently reported a value of $-12.2 \mathrm{kcal} \mathrm{mol}^{-1}$ at the PW91/TZP level. Beichert and Schrems ${ }^{3}$ did not calculate the free energy of hydration at $298 \mathrm{~K}$. However, the value of -6.3 $\mathrm{kcal} \mathrm{mol}{ }^{-1}$ reported by them at $230 \mathrm{~K}$ and at the MP2/6$311++\mathrm{G}(2 \mathrm{~d}, 2 \mathrm{p}) / / \mathrm{MP} 2 / 6-31 \mathrm{G}^{* *}$ level is significantly lower than the value of $-2.9 \mathrm{kcal} \mathrm{mol}^{-1}$ given by Bandy and Ianni at 223 $\mathrm{K}$. The experimental value given by Hanson and Eisele ${ }^{10}$ (at $298 \mathrm{~K}$ ) is $-3.6 \pm 1 \mathrm{kcal} \mathrm{mol}^{-1}$. The reported values of hydration entropies also vary considerably; ranging from $-30.6 \mathrm{cal} / \mathrm{K} \mathrm{mol}$ (Bandy and Ianni) to $+32.6 \mathrm{cal} / \mathrm{K} \mathrm{mol}$ (Al Natsheh et al.). The 
TABLE 1: Thermochemical Parameters for the Reaction $\mathrm{H}_{2} \mathrm{SO}_{4}+\mathrm{H}_{2} \mathrm{O} \leftrightarrow \mathrm{H}_{2} \mathrm{SO}_{4} \cdot \mathrm{H}_{2} \mathrm{O}^{a}$

\begin{tabular}{|c|c|c|c|c|c|}
\hline $\begin{array}{l}\text { method/ } \\
\text { basis set }\end{array}$ & $\begin{array}{c}\Delta E_{0} / \\
\mathrm{kcal} \mathrm{mol}^{-1}\end{array}$ & $\begin{array}{c}\Delta \mathrm{ZPE} / \\
\mathrm{kcal} \mathrm{mol}^{-1}\end{array}$ & $\begin{array}{c}\Delta H / \\
\mathrm{kcal} \mathrm{mol}^{-1}\end{array}$ & $\begin{array}{c}\Delta S / \\
\mathrm{cal} \mathrm{K} \\
\end{array}$ & $\begin{array}{c}\Delta G / \\
\mathrm{kcal} \mathrm{mol}^{-1}\end{array}$ \\
\hline $\mathrm{HF} / 6-311++\mathrm{G}(2 \mathrm{~d}, 2 \mathrm{p})^{b}$ & -9.7 & & & & \\
\hline $\mathrm{MP} 2 / 6-311++\mathrm{G}(2 \mathrm{~d}, 2 \mathrm{p})^{b}$ & -12.5 & $2.6^{c}$ & & & $-6.3(230 \mathrm{~K})^{d}$ \\
\hline $\mathrm{B} 3 \mathrm{LYP} / 6-311++\mathrm{G}(2 \mathrm{~d}, 2 \mathrm{p})^{e}$ & -11.4 & 2.3 & -9.7 & -30.6 & -0.6 \\
\hline B3LYP/D95(d,p $)^{f}$ & -15.1 & 2.5 & -13.4 & -30.4 & -4.3 \\
\hline B3LYP/D95++ $(\mathrm{d}, \mathrm{p})^{f}$ & -12.8 & 2.4 & -11.1 & -29.3 & -2.4 \\
\hline PW91/DNP & -13.4 & & & & -2.5 \\
\hline $\begin{array}{l}\mathrm{PW} 91 / \mathrm{TZP}^{h} \\
\text { exprimental }\end{array}$ & & & -2.6 & 32.6 & $\begin{array}{l}-12.3 \\
-3.6+1\end{array}$ \\
\hline
\end{tabular}

${ }^{a} \Delta E_{0}, \Delta Z \mathrm{PE}, \Delta H, \Delta S$ and $\Delta G$ are the changes in electronic energy, zero-point energy, enthalpy, entropy and Gibbs free energy, respectively. Note that $-\Delta E_{0}$ is often also referred to as the binding energy. All values correspond to $1 \mathrm{~atm}$ and $298 \mathrm{~K}$, unless otherwise stated. ${ }^{b}$ Beichert and Schrems. ${ }^{3}{ }^{c}$ Calculated using the 6-31G ${ }^{* *}$ basis set. ${ }^{d}$ Calculated using the 6-31G ${ }^{* *}$ basis set, and at $230 \mathrm{~K}$. ${ }^{e}$ Bandy and Ianni. ${ }^{4}{ }^{f}$ Re et al. ${ }^{5}$ Note that their reported value of $\Delta S$ corresponded to -1 times the $\Delta S$ value given here, as they used a different sign convention. ${ }^{g}$ Ding et al. ${ }^{6}{ }^{h} \mathrm{Al}$ Natsheh et al. ${ }^{7}$ Note that the temperature used was 298.15 K, not 298 K. ${ }^{i}$ Hanson and Eisele. ${ }^{10}$

TABLE 2: Thermochemical Parameters for the Reaction $\mathrm{H}_{2} \mathrm{SO}_{4}+\mathrm{NH}_{3} \leftrightarrow \mathrm{H}_{2} \mathrm{SO}_{4} \cdot \mathrm{NH}_{3}{ }^{a}$

\begin{tabular}{|c|c|c|c|c|c|}
\hline $\begin{array}{l}\text { method/ } \\
\text { basis set }\end{array}$ & $\begin{array}{c}\Delta E_{0} / \\
\mathrm{kcal} \mathrm{mol}^{-1}\end{array}$ & $\begin{array}{c}\Delta \mathrm{ZPE} / \\
\mathrm{kcal} \mathrm{mol}^{-1}\end{array}$ & $\begin{array}{c}\Delta H / \\
\mathrm{kcal} \mathrm{mol}^{-1}\end{array}$ & $\begin{array}{c}\Delta S / \\
\text { cal K} \mathrm{K}^{-1} \mathrm{~mol}^{-1}\end{array}$ & $\begin{array}{c}\Delta G / \\
\mathrm{kcal} \mathrm{mol}^{-1}\end{array}$ \\
\hline 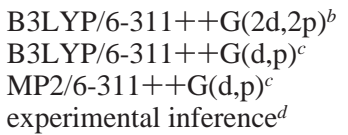 & $\begin{array}{l}-14.6 \\
-16.49 \\
-16.37\end{array}$ & $\begin{array}{l}1.8 \\
1.79 \\
1.69\end{array}$ & -13.76 & -30.91 & -4.54 \\
\hline
\end{tabular}

${ }^{a}$ The definitions of the parameters are the same as in Table 1 . All values correspond to $1 \mathrm{~atm}$ and $298 \mathrm{~K} .{ }^{b}$ Ianni and Bandy. ${ }^{9}{ }^{c}$ Larson et al. ${ }^{8}$ ${ }^{d}$ Eisele and Hanson. ${ }^{11}$

thermochemical parameters reported by different authors for the reaction $\mathrm{H}_{2} \mathrm{SO}_{4}+\mathrm{H}_{2} \mathrm{O} \leftrightarrow \mathrm{H}_{2} \mathrm{SO}_{4} \cdot \mathrm{H}_{2} \mathrm{O}$ are presented in Table 1.

Similar discrepancies exist in the case of ammonium hydrogen sulfate, though there are fewer studies to compare. The only reported value for the free energy change of the reaction $\mathrm{H}_{2}$ $\mathrm{SO}_{4}+\mathrm{NH}_{3} \leftrightarrow \mathrm{H}_{2} \mathrm{SO}_{4} \cdot \mathrm{NH}_{3}$ is $-4.54 \mathrm{kcal} \mathrm{mol}^{-1}$ (at $298 \mathrm{~K}$ and 1 atm) by Ianni and Bandy, ${ }^{9}$ calculated at the B3LYP/6$311++\mathrm{G}(2 \mathrm{~d}, 2 \mathrm{p})$ level. However, the electronic energy changes given by Larson et al. ${ }^{8}$ at the B3LYP/6-311++G(d,p) and MP2/ $6-311++\mathrm{G}(\mathrm{d}, \mathrm{p})$ levels are about $2 \mathrm{kcal} \mathrm{mol}^{-1}$ lower, as can be seen from Table 2. Also, by comparison to the $\mathrm{H}_{2} \mathrm{SO}_{4} \cdot \mathrm{H}_{2} \mathrm{O}$ results it might also be expected that computations using other method/basis set combinations could yield significantly more negative free energies. There are no direct experimental measurements of the free energy of this reaction, but on the basis of measured concentrations of larger $\left(\mathrm{H}_{2} \mathrm{SO}_{4}\right)_{n} \cdot\left(\mathrm{NH}_{3}\right)_{m}$ (with $n \geq 2$ ) clusters, Eisele and Hanson ${ }^{11}$ inferred that the $\Delta G$ value should be around $-8 \mathrm{kcal} \mathrm{mol}^{-1}$.

All the earlier studies computed the zero-point energies and vibrational contributions to the free energy using the harmonic approximation. The only study to account for basis-set superposition was that of Beichert and Schrems, ${ }^{3}$ who found that the basis set superposition error (BSSE; estimated at the uncorrected equilibrium geometry by the counterpoise method ${ }^{12}$ ) was significant (up to $1.4 \mathrm{kcal} \mathrm{mol}^{-1}$ ) for the $6-31 \mathrm{G}^{* *}$ basis set but smaller than $0.25 \mathrm{kcal} \mathrm{mol}^{-1}$ for the larger $6-311++\mathrm{G}(2 \mathrm{~d}, 2 \mathrm{p})$ basis.

\section{Computational Details}

All our ab initio and density functional theory (DFT) calculations have been performed using the Gaussian 03 program suite. ${ }^{13}$ All the geometries were converged to a rootmean-square (RMS) and maximum force of less than $3 \times 10^{-4}$ and $4.5 \times 10^{-4} \mathrm{au}$, respectively. For the anharmonic vibrational frequency calculations, the criteria were $10^{-5}$ and $1.5 \times 10^{-5}$ $\mathrm{au}$, respectively. The convergence with respect to the electronic energy in the self-consistent field (SCF) step was $1 \times 10^{-6}$ au.
For the DFT calculations, the standard integration grid was used, except for the anharmonic vibrational calculations, in which the ultrafine grid was used. For estimation of the basis set superposition energy, the counterpoise correction ${ }^{12}$ (CP) was applied to both the energy and geometry. The perturbative method by which the anharmonic vibrational frequencies were calculated is described in ref 14 .

The methods we used were the B3LYP hybrid functional, ${ }^{15,16}$ the PW91 density functional ${ }^{17}$ and the second-order MøllerPlesset perturbation theory ${ }^{18}$ MP2. Further calculations were also carried out using the coupled cluster method $\operatorname{CCSD}(\mathrm{T}) .{ }^{19}$ The basis sets included were the $\mathrm{D} 95++(\mathrm{d}, \mathrm{p})$ set,${ }^{20}$ the somewhat larger $6-311++G(2 d, 2 p)$ set $^{21-23}$ and the new correlationconsistent polarized split-valence sets cc-pV(T+d)Z and aug$\mathrm{cc}-\mathrm{pV}(\mathrm{T}+\mathrm{d}) \mathrm{Z}$ sets, ${ }^{24}$ which are improved version of the standard cc-pVTZ and aug-cc-pVTZ sets ${ }^{25,26}$ and have been shown to produce more accurate results for sulfur-containing molecules. ${ }^{27,28}$ At the B3LYP level, the cc-pV(D+d)Z, aug-cc-pV$(\mathrm{D}+\mathrm{d}) \mathrm{Z}, \mathrm{cc}-\mathrm{pV}(\mathrm{Q}+\mathrm{d}) \mathrm{Z}$ and aug-cc-pV $(\mathrm{Q}+\mathrm{d}) \mathrm{Z}$ basis sets were also tested.

\section{Results and Discussion}

Thermochemical Parameters. The thermochemical parameters for the reactions $\mathrm{H}_{2} \mathrm{SO}_{4}+\mathrm{H}_{2} \mathrm{O} \leftrightarrow \mathrm{H}_{2} \mathrm{SO}_{4} \cdot \mathrm{H}_{2} \mathrm{O}$ and $\mathrm{H}_{2}-$ $\mathrm{SO}_{4}+\mathrm{NH}_{3} \leftrightarrow \mathrm{H}_{2} \mathrm{SO}_{4} \cdot \mathrm{NH}_{3}$, calculated using three different methods and four different basis sets, and both with and without counterpoise corrections, are presented in Tables 3 and 4, respectively. (For the largest basis set aug-cc-pV(T+d)Z, and methods other than B3LYP, only electronic energies were calculated due to computational limitations.) It should be noted that in test calculations, only small (on the order of $0.05 \mathrm{kcal}$ $\mathrm{mol}^{-1}$ with respect to the reaction energies) differences were observed between the cc-pVTZ and cc-pV(T+d)Z basis sets. This is unsurprising, as the bonding pattern of the sulfur atom itself does not change during cluster formation. However, as the addition of the extra d-orbital on sulfur was not computationally very costly, and in principle should improve the accuracy of the calculation, we have used the revised basis sets throughout this study. 
TABLE 3: Thermochemical Parameters for the Reaction $\mathrm{H}_{2} \mathrm{SO}_{4}+\mathrm{H}_{2} \mathrm{O} \leftrightarrow \mathrm{H}_{2} \mathrm{SO}_{4} \cdot \mathrm{H}_{2} \mathrm{O}$ at $298 \mathrm{~K}$ and 1 Atm, Using Different Methods and Basis Sets, with and without Counterpoise Corrections to the Energy and Geometry ${ }^{a}$

\begin{tabular}{|c|c|c|c|c|c|}
\hline $\begin{array}{l}\text { method/ } \\
\text { basis set }\end{array}$ & $\begin{array}{c}\Delta E_{0} / \\
\mathrm{kcal} \mathrm{mol}^{-1}\end{array}$ & $\begin{array}{c}\Delta \mathrm{ZPE} / \\
\mathrm{kcal} \mathrm{mol}^{-1}\end{array}$ & $\begin{array}{c}\Delta H / \\
\mathrm{kcal} \mathrm{mol}^{-1}\end{array}$ & $\begin{array}{c}\Delta S / \\
\mathrm{cal} \mathrm{K}^{-1} \mathrm{~mol}^{-1}\end{array}$ & $\begin{array}{c}\Delta G / \\
\mathrm{kcal} \mathrm{mol}^{-1}\end{array}$ \\
\hline \multirow[t]{2}{*}{ B3LYP/D95++(d,p) } & $-12.757^{b}$ & $2.309^{b}$ & $-11.101^{b}$ & $-29.25^{b}$ & $-2.380^{b}$ \\
\hline & $-11.729^{c}$ & $2.223^{c}$ & $-10.131^{c}$ & $-29.06^{c}$ & $-1.465^{c}$ \\
\hline \multirow[t]{2}{*}{ B3LYP/6-311++G(2d,2p) } & $-11.332^{b}$ & $2.275^{b}$ & $-9.706^{b}$ & $-29.21^{b}$ & $-0.998^{b}$ \\
\hline & $-10.641^{c}$ & $2.213^{c}$ & $-9.038^{c}$ & $-28.92^{c}$ & $-0.417^{c}$ \\
\hline \multirow[t]{2}{*}{ B3LYP/cc-pV(T+d)Z } & $-13.541^{b}$ & $2.337^{b}$ & $-11.904^{b}$ & $-29.62^{b}$ & $-3.072^{b}$ \\
\hline & $-11.477^{c}$ & $2.266^{c}$ & $-9.858^{c}$ & $-29.23^{c}$ & $-1.143^{c}$ \\
\hline $\begin{array}{l}\text { B3LYP/ } \\
\text { aug-cc-pV(T+d)Z }\end{array}$ & $\begin{array}{l}-11.159^{b} \\
-11.001^{c}\end{array}$ & $2.285^{b}$ & $-9.552^{b}$ & $-29.471^{b}$ & $-0.765^{b}$ \\
\hline \multirow[t]{2}{*}{ PW91/D95++(d,p) } & $-14.138^{b}$ & $2.245^{b}$ & $-12.639^{b}$ & $-30.05^{b}$ & $-3.682^{b}$ \\
\hline & $-13.002^{c}$ & $2.173^{c}$ & $-11.553^{c}$ & $-29.09^{c}$ & $-2.639^{c}$ \\
\hline \multirow[t]{2}{*}{ PW91/6-311++G(2d,2p) } & $-12.978^{b}$ & $2.213^{b}$ & $-11.510^{b}$ & $-30.04^{b}$ & $-2.553^{b}$ \\
\hline & $-12.102^{c}$ & $2.154^{c}$ & $-10.655^{c}$ & $-29.78^{c}$ & $-1.776^{c}$ \\
\hline \multirow[t]{2}{*}{ PW91/cc-pV(T+d)Z } & $-15.581^{b}$ & $2.276^{b}$ & $-14.117^{b}$ & $-30.56^{b}$ & $-5.006^{b}$ \\
\hline & $-12.986^{c}$ & $2.223^{c}$ & $-11.521^{c}$ & $-30.19^{c}$ & $-2.521^{c}$ \\
\hline PW91/ & $-12.741^{b}$ & & & & \\
\hline \multirow{3}{*}{$\begin{array}{l}\text { aug-cc-pV(T+d)Z } \\
\text { MP2/D95++(d,p) }\end{array}$} & $-12.519^{c}$ & & & & \\
\hline & $-13.747^{b}$ & $2.364^{b}$ & $-11.985^{b}$ & $-28.78^{b}$ & $-3.404^{b}$ \\
\hline & $-10.754^{c}$ & $2.166^{c}$ & $-9.059^{c}$ & $-27.73^{c}$ & $-0.791^{c}$ \\
\hline \multirow[t]{2}{*}{ MP2/6-311++G(2d,2p) } & $-12.577^{b}$ & $2.339^{b}$ & $-10.877^{b}$ & $-29.15^{b}$ & $-2.184^{b}$ \\
\hline & $-10.682^{c}$ & $2.198^{c}$ & $-9.022^{c}$ & $-28.37^{c}$ & $-0.564^{c}$ \\
\hline \multirow[t]{2}{*}{ MP2/ cc-pV(T+d)Z } & $-14.361^{b}$ & $2.324^{b}$ & $-12.74^{b}$ & $-29.66^{b}$ & $-3.896^{b}$ \\
\hline & $-11.669^{c}$ & $2.257^{c}$ & $-10.01^{c}$ & $-28.90^{c}$ & $-1.399^{c}$ \\
\hline $\begin{array}{l}\text { MP2/ } \\
\text { aug-cc-pV(T+d)Z }\end{array}$ & $\begin{array}{l}-13.016^{b} \\
-11.940^{c}\end{array}$ & & & & \\
\hline
\end{tabular}

${ }^{a}$ The definitions of the parameters are the same as in Table $1 .{ }^{b}$ Without counterpoise corrections. ${ }^{c}$ With counterpoise corrections to both the geometry and energy.

TABLE 4: Thermochemical Parameters for the Reaction $\mathrm{H}_{2} \mathrm{SO}_{4}+\mathrm{NH}_{3} \leftrightarrow \mathrm{H}_{2} \mathrm{SO}_{4} \cdot \mathrm{NH}_{3}$ at $298 \mathrm{~K}$ and 1 atm (in kcal mol $\mathrm{m}^{-1}$ ) Using Different Methods and Basis Sets, with and without Counterpoise Corrections to the Energy and Geometry ${ }^{a}$

\begin{tabular}{|c|c|c|c|c|c|}
\hline $\begin{array}{l}\text { method/ } \\
\text { basis set }\end{array}$ & $\begin{array}{c}\Delta E_{0} / \\
\mathrm{kcal} \mathrm{mol}^{-1}\end{array}$ & $\begin{array}{c}\Delta \mathrm{ZPE} / \\
\mathrm{kcal} \mathrm{mol}^{-1}\end{array}$ & $\begin{array}{c}\Delta H / \\
\mathrm{kcal} \mathrm{mol}^{-1}\end{array}$ & $\begin{array}{c}\Delta S / \\
\mathrm{cal} \mathrm{K}^{-1} \mathrm{~mol}^{-1}\end{array}$ & $\begin{array}{c}\Delta G / \\
\mathrm{kcal} \mathrm{mol}^{-1}\end{array}$ \\
\hline B3LYP/D95++(d,p) & $\begin{array}{l}-17.267^{b} \\
-16.073^{c}\end{array}$ & $\begin{array}{l}1.782^{b} \\
1.765^{c}\end{array}$ & $\begin{array}{l}-16.015^{b} \\
-14.813^{c}\end{array}$ & $\begin{array}{l}-27.97^{b} \\
-27.82^{c}\end{array}$ & $\begin{array}{l}-7.675^{b} \\
-6.520^{c}\end{array}$ \\
\hline B3LYP/ & $-15.060^{b}$ & $1.790^{b}$ & $-15.060^{b}$ & $-27.41^{b}$ & $-5.572^{b}$ \\
\hline $6-311++G(2 d, 2 p)$ & $-14.489^{c}$ & $1.802^{c}$ & $-13.150^{c}$ & $-27.39^{c}$ & $-4.983^{c}$ \\
\hline B3LYP/ cc-pV(T+d)Z & $\begin{array}{l}-16.704^{b} \\
-14.809^{c}\end{array}$ & $\begin{array}{l}1.844^{b} \\
1.866^{c}\end{array}$ & $\begin{array}{l}-15.361^{b} \\
-13.419^{c}\end{array}$ & $\begin{array}{l}-27.85^{b} \\
-27.61^{c}\end{array}$ & $\begin{array}{l}-7.058^{b} \\
-5.189^{c}\end{array}$ \\
\hline $\begin{array}{l}\text { B3LYP/ } \\
\text { aug-cc-pV(T+d)Z }\end{array}$ & $\begin{array}{l}-14.922^{b} \\
-14.767^{c}\end{array}$ & $1.817^{b}$ & $-13.594^{b}$ & $-27.60^{b}$ & $-5.365^{b}$ \\
\hline PW91/D95++(d,p) & $\begin{array}{l}-19.659^{b} \\
-18.277^{c}\end{array}$ & $\begin{array}{l}1.525^{b} \\
1.516^{c}\end{array}$ & $\begin{array}{l}-18.724^{b} \\
-17.320^{c}\end{array}$ & $\begin{array}{l}-28.65^{b} \\
-28.39^{c}\end{array}$ & $\begin{array}{r}-10.183^{b} \\
-8.855^{c}\end{array}$ \\
\hline PW91/6-311++G(2d,2p) & $\begin{array}{l}-17.496^{b} \\
-16.781^{c}\end{array}$ & $\begin{array}{l}1.491^{b} \\
1.481^{c}\end{array}$ & $\begin{array}{l}-16.539^{b} \\
-15.811^{c}\end{array}$ & $\begin{array}{l}-28.22^{b} \\
-28.01^{c}\end{array}$ & $\begin{array}{l}-8.124^{b} \\
-7.461^{c}\end{array}$ \\
\hline PW91/ cc-pV(T+d)Z & $\begin{array}{l}-19.199^{b} \\
-16.964^{c}\end{array}$ & $\begin{array}{l}1.607^{b} \\
1.643^{c}\end{array}$ & $\begin{array}{l}-18.154^{b} \\
-15.845^{c}\end{array}$ & $\begin{array}{l}-28.57^{b} \\
-28.18^{c}\end{array}$ & $\begin{array}{l}-9.636^{b} \\
-7.443^{c}\end{array}$ \\
\hline $\begin{array}{l}\text { PW91/ } \\
\text { aug-cc-pV(T+d)Z }\end{array}$ & $\begin{array}{l}-17.306^{b} \\
-17.097^{c}\end{array}$ & & & & \\
\hline MP2/D95++(d,p) & $\begin{array}{l}-18.229^{b} \\
-14.715^{c}\end{array}$ & $\begin{array}{l}1.784^{b} \\
1.906^{c}\end{array}$ & $\begin{array}{l}-16.194^{b} \\
-13.219^{c}\end{array}$ & $\begin{array}{l}-27.56^{b} \\
-26.68^{c}\end{array}$ & $\begin{array}{l}-8.719^{b} \\
-5.265^{c}\end{array}$ \\
\hline $\mathrm{MP} 2 / 6-311++\mathrm{G}(2 \mathrm{~d}, 2 \mathrm{p})$ & $\begin{array}{l}-16.406^{b} \\
-14.512^{c}\end{array}$ & $\begin{array}{l}1.877^{b} \\
1.904^{c}\end{array}$ & $\begin{array}{l}-14.999^{b} \\
-13.033^{c}\end{array}$ & $\begin{array}{l}-27.34^{b} \\
-27.06^{c}\end{array}$ & $\begin{array}{l}-6.849^{b} \\
-4.965^{c}\end{array}$ \\
\hline MP2/ cc-pV(T+d)Z & $\begin{array}{l}-17.900^{b} \\
-15.217^{c}\end{array}$ & $\begin{array}{l}1.803^{b} \\
1.889^{c}\end{array}$ & $\begin{array}{l}-16.593^{b} \\
-13.779^{c}\end{array}$ & $\begin{array}{l}-27.77^{b} \\
-27.41^{c}\end{array}$ & $\begin{array}{l}-8.314^{b} \\
-5.606^{c}\end{array}$ \\
\hline $\begin{array}{l}\text { MP2/ } \\
\text { aug-cc-pV(T+d)Z }\end{array}$ & $\begin{array}{l}-17.067^{b} \\
-15.927^{c}\end{array}$ & & & & \\
\hline
\end{tabular}

${ }^{a}$ The definitions of the parameters are the same as in Table $1 .{ }^{b}$ Without counterpoise corrections. ${ }^{c}$ With counterpoise corrections to both the geometry and energy.

Clearly, the choice of method and basis set has an enormous influence on the formation energies of atmospherically relevant cluster structures. The large difference for example between the results obtained by Bandy and Ianni ${ }^{4}$ and $\mathrm{Al}$ Natsheh et al. $^{7}$ are thus explained at least partially by the fact that Bandy and Ianni used a method/basis set combination which produces exceptionally low stabilities, whereas $\mathrm{Al}$ Natsheh et al. employed a functional yielding exceptionally high stabilities. The Slatertype orbital-based TZP basis set used in their calculations was unfortunately not available for the Gaussian 03 program, and we could not investigate further reasons for why their absolute values for the free energies of reaction are still twice as large as our largest PW91 values.

The effect of basis set superposition error on the electronic energies, enthalpies and free energies was found to be very large (several $\mathrm{kcal} \mathrm{mol}^{-1}$ ) for almost all the method/basis set combinations studied, the sole exceptions being the DFT/augcc-pV $(\mathrm{T}+\mathrm{d}) \mathrm{Z}$ calculations. This is in contrast to the earlier findings of Beichert and Schrems, ${ }^{3}$ who found the BSSE to be insignificant for the medium-sized $6-311++\mathrm{G}(2 \mathrm{~d}, 2 \mathrm{p})$ basis set. 
For example, at the MP2/D95++(d,p) level, the absolute value of the free energy of hydration of sulfuric acid decreases by a factor of 4 (from 3.40 to $0.79 \mathrm{kcal} \mathrm{mol}^{-1}$ ) when the counterpoise correction is applied. Clearly, BSSE should be taken into account in any future studies if even semiquantitative results are desired. This will probably present considerably difficulties for studies on larger clusters with, e.g., 5-10 molecules, as the computational effort of applying the counterpoise correction (CP) increases rapidly with the number of fragments. In such cases, it may be necessary to use simplified versions of the full $\mathrm{CP}$ method, and to apply the CP correction only to the energy, not the geometry. Our studies indicate that for our two-molecule clusters, neglecting the $\mathrm{CP}$ correction to the geometry causes errors on the order of $0.1 \mathrm{kcal} \mathrm{mol}^{-1}$ with respect to both the binding energies and the thermal contributions to the reaction free energy. Thus, although "energy-only" correction schemes do not remove all of the BSSE, they still decrease it by an order of magnitude compared to uncorrected calculations.

Application of the counterpoise correction decreases the differences between results obtained using different methods and basis sets. For example, the counterpoise-corrected B3LYP and MP2 results are quite close to each other for each basis set, as well as the counterpoise-corrected cc-pV(T+d)Z and augcc-pV $(\mathrm{T}+\mathrm{d}) \mathrm{Z}$ results for each method. The differences between correlation-consistent basis sets and the $\mathrm{D} 95++(\mathrm{d}, \mathrm{p})$ and $6-311++\mathrm{G}(2 \mathrm{~d}, 2 \mathrm{p})$ sets are still large, and the counterpoisecorrected PW91 results differ significantly from the corresponding B3LYP and MP2 results.

Adding additional augmented functions to the cc-pV(T+d)Z basis set decreases the BSSE by an order of magnitude for the DFT calculations, and by about half for the MP2 calculations. The aug-cc-pV $(\mathrm{T}+\mathrm{d}) \mathrm{Z}$ energies, both with and without counterpoise corrections, obtained using different methods are also slightly more compatible than the cc-pV $(\mathrm{T}+\mathrm{d}) \mathrm{Z}$ energies. The augmented basis functions clearly seem to improve the description of the intermolecular interaction. However, it should be noted that the aug-cc-pV(T+d)Z potential energy surfaces, especially the counterpoise-corrected ones, are very flat near the energy minimum. This resulted in long and computationally expensive geometry optimization runs.

The choice of method and basis set, as well as the counterpoise correction, has a relatively small effect on the vibrational zero-point energy (ZPE), entropy and also the thermal vibrational contributions to the various properties (not shown here). The difference between the total vibrational contributions to the reaction free energy between the computationally cheapest (B3LYP/D95++(d,p) and PW91/D95++(d,p)) and most expensive (MP2/cc-pV(T+d)Z) ) calculations is less than $0.2 \mathrm{kcal}$ $\mathrm{mol}^{-1}$ for both species studied. The approach of calculating the electronic energies at a higher level than the vibrational properties (employed for example by Beichert and Schrems) thus seems to be justified. This will be discussed further below.

For ammonium hydrogen sulfate at the PW91/cc-pV(T+d)Z level and with all MP2 calculations, the ZPE change increases upon the application of counterpoise corrections. This is probably indicative of the low accuracy of the ZPEs computed using the harmonic approximation rather than any real physical effect.

It should be noted that for many atmospheric applications (such as nucleation studies investigating the role of ammonia in new-particle formation ${ }^{29,30}$ ), the difference between the energies of the $\mathrm{H}_{2} \mathrm{SO}_{4}+\mathrm{H}_{2} \mathrm{O} \leftrightarrow \mathrm{H}_{2} \mathrm{SO}_{4} \cdot \mathrm{H}_{2} \mathrm{O}$ and $\mathrm{H}_{2} \mathrm{SO}_{4}+$ $\mathrm{NH}_{3} \leftrightarrow \mathrm{H}_{2} \mathrm{SO}_{4} \cdot \mathrm{NH}_{3}$ reactions may be equally or more relevant than the energy values themselves. It is therefore fortunate that, even though the reaction energies obtained at different methods vary by several kcal mol${ }^{-1}$, the values of $\Delta G\left(\mathrm{H}_{2} \mathrm{SO}_{4}+\mathrm{H}_{2} \mathrm{O} \leftrightarrow\right.$ $\left.\mathrm{H}_{2} \mathrm{SO}_{4} \cdot \mathrm{H}_{2} \mathrm{O}\right)-\Delta G\left(\mathrm{H}_{2} \mathrm{SO}_{4}+\mathrm{NH}_{3} \leftrightarrow \mathrm{H}_{2} \mathrm{SO}_{4} \cdot \mathrm{NH}_{3}\right)$ or $\Delta E_{0}\left(\mathrm{H}_{2}-\right.$ $\left.\mathrm{SO}_{4}+\mathrm{H}_{2} \mathrm{O} \leftrightarrow \mathrm{H}_{2} \mathrm{SO}_{4} \cdot \mathrm{H}_{2} \mathrm{O}\right)-\Delta E_{0}\left(\mathrm{H}_{2} \mathrm{SO}_{4}+\mathrm{NH}_{3} \leftrightarrow \mathrm{H}_{2} \mathrm{SO}_{4} \cdot\right.$ $\mathrm{NH}_{3}$ ) vary considerably less. The difference in the free energies varies between 4.0 and $4.9 \mathrm{kcal} \mathrm{mol}^{-1}$ and the difference in the electronic energies between 3.8 and $4.6 \mathrm{kcal} \mathrm{mol}^{-1}$, for the counterpoise-corrected results obtained using the correlationconsistent basis sets cc-pV(T+d)Z and (for the electronic energies) aug-cc-pV(T+d)Z. Larger variations are observed if the smaller basis sets are taken into account. Again, the B3LYP and MP2 results agree even more closely (to within ca. $0.2 \mathrm{kcal}$ $\mathrm{mol}^{-1}$ ), whereas the PW91 method predicts systematically bigger differences between the reaction energies.

Geometrical Parameters and QTAIM Analysis. The electronic charge densities generated by the ab initio and DFT calculations were analyzed with the AIMPAC ${ }^{31}$ and AIM 2000 programs, ${ }^{32}$ using the quantum theory of atoms in molecules ${ }^{33}$ (QTAIM) to determine the bond critical points and bond paths. The AIM2000 package was used to identify the critical points (CP) of the electron densities $\rho(\mathbf{x}, \mathbf{y}, \mathbf{z})$ in each cluster studied, and to trace the bond paths present. The AIMPAC program was then used to calculate the values of various parameters at the critical points. As discussed, e.g., in ref 34, the existence of a $(3,-1)^{1} \mathrm{CP}$ (also known as bond critical point, $\mathrm{BCP}$ ) between two atoms is a necessary and sufficient criterion for the existence of a chemical bond between them. The line of maximum density passing through the BCP and linking the nuclei of the two atoms is then called a bond path. Similarly, $(3,+1)$. CPs correspond to ring structures and $(3,+3) \mathrm{CPs}$ to cage structures. [Critical points are points where the gradient of a function is zero. The type of critical point is indicated by the notation $(r, s)$, where the rank $(r)$ is the number of nonzero eigenvalues of the second derivative matrix and the signature $(s)$ is the sum of the signs of the eigenvalues. Thus, a $(3,-1)$ critical point has three nonzero eigenvalues, two of which are negative.]

The values of the electron density $\rho$ and its Laplacian $\nabla^{2} \rho$, as well as the electronic kinetic, potential and total energies ( $G, V$ and $E$, respectively; see ref 34 for definitions) at the BCP can be used to characterize the nature of the bonding interaction. For example, closed-shell interactions correspond to positive values of $\nabla^{2} \rho_{\mathrm{BCP}}$ and $E_{\mathrm{BCP}}$, whereas covalent bonds correspond to negative values. (Values of various parameters at the bond critical point are denoted with the subscript BCP.) Also, the strength of the bonding interaction correlates with $\rho_{\mathrm{BCP}}$, though the functional form of the correlation is not generally known. For a set of H-bonded complexes, Koch and Popelier ${ }^{35}$ found the correlation between the H-bond energy and $\rho_{\mathbf{B C P}}$ to be linear as long as the acceptor atom remained unchanged. In characterizing the H-bonds of our cluster structures, we have adopted the classification used by Rozas et al: ${ }^{36}$ a H-bond is defined as weak if $\nabla^{2} \rho_{\mathrm{BCP}}>0$ and $E_{\mathrm{BCP}}>0$, medium-strength if $\nabla^{2} \rho_{\mathrm{BCP}}$ $>0$ but $E_{\mathrm{BCP}}<0$, and strong if $\nabla^{2} \rho_{\mathrm{BCP}}<0$ and $E_{\mathrm{BCP}}<0$.

Both the $\mathrm{H}_{2} \mathrm{SO}_{4} \cdot \mathrm{H}_{2} \mathrm{O}$ and $\mathrm{H}_{2} \mathrm{SO}_{4} \cdot \mathrm{NH}_{3}$ clusters contain two possible hydrogen bonds: a $\mathrm{SOH} \cdots \mathrm{X}$ bond and a $\mathrm{XH} \cdots \mathrm{O}=\mathrm{S}$ bond (where $\mathrm{X}=\mathrm{O}$ or $\mathrm{N}$ ). The structures of the $\mathrm{H}_{2} \mathrm{SO}_{4} \cdot \mathrm{H}_{2} \mathrm{O}$ and $\mathrm{H}_{2} \mathrm{SO}_{4} \cdot \mathrm{NH}_{3}$ clusters are shown schematically in Figures 1 and 2, along with the locations of the BCPs corresponding to hydrogen bonds. (Figures 1 and 2 were created using the MOLEKEL ${ }^{37,38}$ program.) The hydrogen bond lengths for the $\mathrm{H}_{2} \mathrm{SO}_{4} \cdot \mathrm{H}_{2} \mathrm{O}$ and $\mathrm{H}_{2} \mathrm{SO}_{4} \cdot \mathrm{NH}_{3}$ clusters are shown in Tables 5 and 6 for both uncorrected and counterpoise-corrected optimum geometries. The associated values for the electron density, its Laplacian and the total energy density at the bond critical points, 


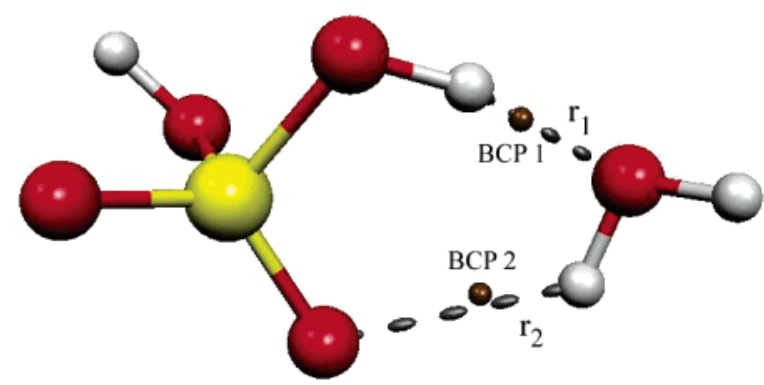

Figure 1. Structure of the $\mathrm{H}_{2} \mathrm{SO}_{4} \cdot \mathrm{H}_{2} \mathrm{O}$ cluster. The parameter $r_{1}$ is the distance between the $\mathrm{SOH}$ hydrogen and water oxygen atoms, and $r_{2}$ is the distance between the water hydrogen and $\mathrm{S}=\mathrm{O}$ oxygen. The bond critical points corresponding to the two hydrogen bonds (labeled $\mathrm{BCP}$ 1 and BCP 2) are shown schematically. Note that the actual positions of the atoms and BCPs vary depending on the method used, as shown in Table 5 .

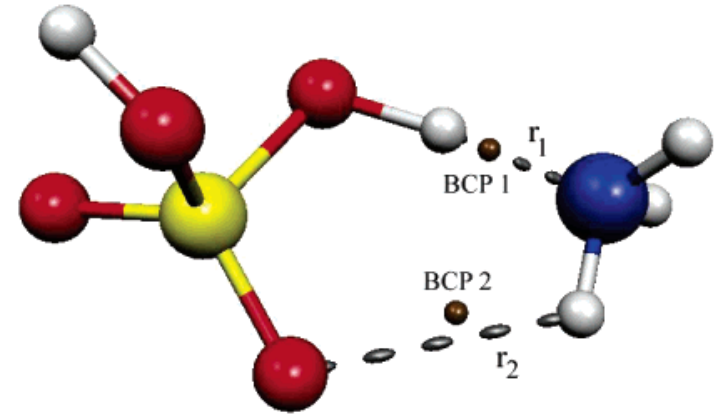

Figure 2. Structure of the $\mathrm{H}_{2} \mathrm{SO}_{4} \cdot \mathrm{NH}_{3}$ cluster. The parameter $r_{1}$ is the distance between the $\mathrm{SOH}$ hydrogen and ammonia nitrogen atoms, and $r_{2}$ is the distance between the ammonia hydrogen and $\mathrm{S}=\mathrm{O}$ oxygen. The bond critical points corresponding to the two hydrogen bonds (labeled BCP 1 and BCP 2) are shown schematically. Note that the actual positions of the atoms and BCPs vary depending on the method used, as shown in Table 6, and that BCP 2 may be missing for some method/basis set combinations.

computed using the AIMPAC program, are also shown. As the counterpoise correction is only applied to the energy and geometry and does not yield a BSSE-free wave function, no "counterpoise-corrected" AIM parameters are given. (The wave functions can, of course, be calculated also at the CP optimum geometry, but they will show little difference to the uncorrected ones, as the wave function is still contaminated by basis set superposition.) We have also calculated a "proton transfer ratio", defined as the ratio of the electron density of the SOH $\cdots X$ (where $\mathrm{X}=\mathrm{O}$ or $\mathrm{N}$ ) $\mathrm{H}$-bond $\mathrm{BCP}$ to that of the $\mathrm{SO}-\mathrm{H} \mathrm{BCP}$, $\rho_{\mathbf{B C P}}(\mathrm{H} \cdots \mathrm{X}) / \rho_{\mathbf{B C P}}(\mathrm{SO}-\mathrm{H})$. The larger the transfer ratio, the more evenly shared the proton is between the donor and acceptor groups. For a transferred proton the ratio should be larger than one.

$\mathrm{H}_{2} \mathrm{SO}_{4} \cdot \mathrm{H}_{2} \mathrm{O}$ Clusters. For $\mathrm{H}_{2} \mathrm{SO}_{4} \cdot \mathrm{H}_{2} \mathrm{O}$, a ring structure with a ring critical point (not shown in Figure 1) and two hydrogen bonds (the corresponding BCPs are indicated in Figure 1) was found with all method/basis set combinations used in this study. The $\mathrm{SOH} \cdots \mathrm{O}$ bond was always of medium strength, with electron density values ranging from 0.042 to $0.063 \mathrm{au}$. The $\mathrm{OH} \cdots \mathrm{O}=\mathrm{S}$ bond was always weak, with electron density values between 0.014 and 0.022 au. It can be seen by comparing Tables 3 and 5 that the higher stabilities (lower reaction free energies) given by the PW91 calculations are associated with shorter hydrogen bonds, higher charge densities at the bond critical points corresponding to the hydrogen bonds and greater degrees of proton transfer. Similarly, the lower stabilities given by calculations using the $6-311++\mathrm{G}(2 \mathrm{~d}, 2 \mathrm{p})$ basis set correspond to longer hydrogen bond paths, lower charge densities and a smaller degree of proton transfer. The B3LYP and MP2 bond lengths are in reasonable agreement with each other for the larger basis sets, whereas the MP2 charge densities are consistently lower than the corresponding DFT ones. This is a quite general phenomenon, as demonstrated, e.g., by the calculations in ref 39. Application of the counterpoise correction increases the length of the stronger H-bond by $0.003-0.019 \AA$ for the DFT calculations and $0.025-0.067 \AA$ for MP2 calculations. As expected, the smallest increases were observed when the aug-cc-pV $(\mathrm{T}+\mathrm{d}) \mathrm{Z}$ basis set was used, for which the BSSE is relatively small. For the DFT/aug-cc-pV(T+d)Z computations, in which the BSSE is only about $0.2 \mathrm{kcal} \mathrm{mol}^{-1}$, the counterpoise correction to the $\mathrm{H}$-bond lengths was insignificant. The increase in length of the weaker H-bond varied more strongly, but the corrections at the MP2 level were again larger than at the DFT levels. In contrast to the electronic energies, neither the application of the counterpoise correction nor the use of additional augmented basis functions led to a systematic decrease in the differences between the bond lengths obtained with different methods.

All the intermolecular $\mathrm{SOH} \cdots \mathrm{O}$ distances calculated with the larger cc-pV $(\mathrm{T}+\mathrm{d}) \mathrm{Z}$ and aug-cc-pV $(\mathrm{T}+\mathrm{d}) \mathrm{Z}$ basis sets are in reasonable agreement with the experimental value of $1.645 \pm$ $0.005 \AA$ reported in the rotational spectroscopic study of Fiaccio et al. ${ }^{40}$ The B3LYP and MP2 values are slightly larger and the PW91 values slightly smaller than the experimental value, but the differences are less than $0.05 \AA$. However, the intermolecular $\mathrm{OH} \cdots \mathrm{O}=\mathrm{S}$ distances calculated with the B3LYP and MP2 methods are considerably $(0.06-0.11 \AA$ for the uncorrected and $0.11-0.16$ for the counterpoise-corrected values) longer than the experimental value of $2.05 \pm 0.01 \AA$, whereas the PW91 values are in good agreement with it. This would seem to support the assertion by al Nathseh et al. that the B3LYP functional predicts too long bond lengths and too low binding energies for weakly bound complexes such as sulfuric acid monohydrate.

$\mathbf{H}_{2} \mathrm{SO}_{4} \cdot \mathrm{NH}_{3}$ Clusters. For the $\mathrm{H}_{2} \mathrm{SO}_{4} \cdot \mathrm{NH}_{3}$ cluster, the situation is more complicated. In the PW91/D95++(d,p), PW91/ 6-311++G(2d,2p) and PW91/cc-pV(T+d)Z calculations, a ring structure with two H-bonds was found. Like in the $\mathrm{H}_{2} \mathrm{SO}_{4} \cdot \mathrm{H}_{2} \mathrm{O}$ cluster, the intermolecular $\mathrm{NH} \cdots \mathrm{O}=\mathrm{S}$ interaction was always weak, and the $\mathrm{SOH} \cdots \mathrm{N}$ interaction of medium strength, except for the PW91/cc-pV(T+d)Z case in which it was strong. However, in the PW91/aug-cc-pV(T+d)Z calculations as well as in all the B3LYP and MP2 calculations, the hydrogen bonding pattern was different. In the B3LYP/6-311++G(2d,2p) and B3LYP/aug-cc-pV(T+d)Z calculations, the second $\mathrm{H}$-bond was missing. In the other B3LYP calculations, the PW91/aug-cc$\mathrm{pV}(\mathrm{T}+\mathrm{d}) \mathrm{Z}$ calculation and also in all MP2 runs, a ring structure containing a highly curved bond path between the $\mathrm{S}=\mathrm{O}$ oxygen and the nitrogen atom of ammonia was seen instead. See Figure 3 for a representative illustration of the three different bonding patterns. This curved bonding interaction either may be an artifact of the Gaussian 03 or AIM 2000 programs or may reflect a genuine bonding interaction. A comparison of, for example, the B3LYP/D95++(d,p) and B3LYP/6-311++G(2d,2p) results seems to indicate that this bonding interaction certainly seems to be stabilizing: the (counterpoise-corrected) reaction free energy is over $1.5 \mathrm{kcal} \mathrm{mol}^{-1}$ higher at the D95++(d,p) level, where the interaction is found, than at the $6-311++\mathrm{G}(2 \mathrm{~d}, 2 \mathrm{p})$ level, where it is absent. A comparison of Tables 4 and 6 also seems to indicate that there is a correlation between BSSE and the anomalous-looking bonding. At the B3LYP level, the curved 
TABLE 5: Hydrogen Bond Lengths and Topological Parameters at the Corresponding Bond $\mathrm{Critical}^{\mathrm{Points}}$ for the $\mathrm{H}_{2} \mathrm{SO}_{4} \cdot \mathrm{H}_{2} \mathrm{O}$ Cluster, Using Different Methods and Basis Sets, with and without Counterpoise Corrections to the Energy and Geometry ${ }^{\mathrm{a}}$

\begin{tabular}{|c|c|c|c|c|c|c|c|c|c|}
\hline $\begin{array}{l}\text { method/ } \\
\text { basis set }\end{array}$ & $\begin{array}{l}r_{1} / \\
\AA\end{array}$ & $\begin{array}{c}\rho_{1} / \\
100 \mathrm{au}\end{array}$ & $\begin{array}{c}\nabla^{2} \rho_{1} / \\
100 \mathrm{au}\end{array}$ & $\begin{array}{c}E_{1} / \\
\text { au }\end{array}$ & $\begin{array}{l}r_{2} / \\
\AA\end{array}$ & $\begin{array}{c}\rho_{2} / \\
100 \mathrm{au}\end{array}$ & $\begin{array}{c}\nabla^{2} \rho_{2} / \\
100 \mathrm{au}\end{array}$ & $\begin{array}{c}E_{2} / \\
\mathrm{au}\end{array}$ & $\begin{array}{l}\text { H-tranfer } \\
\text { ratio }\end{array}$ \\
\hline B3LYP/ & $1.651^{b}$ & 5.131 & 13.23 & -0.607 & $2.231^{b}$ & 1.390 & 5.810 & 0.240 & 0.168 \\
\hline D95++(d,p) & $1.665^{c}$ & & & & $2.232^{c}$ & & & & \\
\hline B3LYP/ & $1.684^{b}$ & 4.640 & 12.04 & -0.470 & $2.202^{b}$ & 1.522 & 5.645 & 0.168 & 0.143 \\
\hline $6-311++G(2 d, 2 p)$ & $1.696^{c}$ & & & & $2.232^{c}$ & & & & \\
\hline B3LYP/ & $1.661^{b}$ & 5.238 & 9.540 & -1.429 & $2.163^{b}$ & 1.607 & 6.478 & 0.290 & 0.165 \\
\hline cc-pV(T+d)Z & $1.677^{c}$ & & & & $2.210^{c}$ & & & & \\
\hline B3LYP/ & $1.673^{b}$ & 5.028 & 9.765 & -1.273 & $2.182^{b}$ & 1.500 & 6.176 & 0.285 & 0.157 \\
\hline aug-cc-pV(T+d)Z & $1.676^{c}$ & & & & $2.185^{c}$ & & & & \\
\hline PW91/ & $1.599^{b}$ & 6.121 & 12.82 & -1.213 & $2.117^{b}$ & 1.783 & 6.763 & 0.213 & 0.212 \\
\hline D95++(d,p) & $1.613^{c}$ & & & & $2.121^{c}$ & & & & \\
\hline PW91/ & $1.622^{b}$ & 5.650 & 11.94 & -0.974 & $2.079^{b}$ & 1.983 & 7.000 & 0.176 & 0.185 \\
\hline $6-311++G(2 d, 2 p)$ & $1.639^{c}$ & & & & $2.102^{c}$ & & & & \\
\hline PW91/ & $1.603^{b}$ & 6.299 & 8.422 & -2.177 & $2.025^{b}$ & 2.215 & 8.092 & 0.241 & 0.210 \\
\hline cc-pV $(T+d) Z$ & $1.622^{c}$ & & & & $2.072^{c}$ & & & & \\
\hline PW91/ & $1.612^{b}$ & 6.092 & 8.853 & -1.982 & $2.060^{b}$ & 2.033 & 7.685 & 0.267 & 0.202 \\
\hline aug-cc-pV(T+d)Z & $1.617^{c}$ & & & & $2.066^{b}$ & & & & \\
\hline MP2/ & $1.683^{b}$ & 4.263 & 14.89 & -0.040 & $2.280^{b}$ & 1.232 & 5.650 & 0.237 & 0.136 \\
\hline D95++(d,p) & $1.750^{c}$ & & & & $2.357^{c}$ & & & & \\
\hline MP2/ & $1.690^{b}$ & 4.176 & 13.61 & -0.215 & $2.176^{b}$ & 1.535 & 6.410 & 0.196 & 0.128 \\
\hline $6-311++G(2 d, 2 p)$ & $1.742^{c}$ & & & & $2.265^{c}$ & & & & \\
\hline MP2/ & $1.640^{b}$ & 5.081 & 11.84 & -1.309 & $2.107^{b}$ & 1.707 & 7.771 & 0.341 & 0.161 \\
\hline$c c-p V(T+d) Z$ & $1.688^{c}$ & & & & $2.214^{c}$ & & & & \\
\hline MP2/ & $1.654^{b}$ & 4.859 & 11.88 & -1.145 & $2.119^{b}$ & 1.662 & 7.711 & 0.340 & 0.154 \\
\hline aug-pV(T+d)Z & $1.679^{c}$ & & & & $2.174^{c}$ & & & & \\
\hline experimental $^{d}$ & $1.645 \pm 0.005$ & & & & $2.05 \pm 0.01$ & & & & \\
\hline
\end{tabular}

${ }^{a} r_{n}$ is the H-bond length, $\rho_{n}$ is the electron density, $\nabla^{2} \rho_{n}$ is its Laplacian and $E_{n}$ is the total electronic energy computed at the bond critical point corresponding to hydrogen bond $n$. Index 1 corresponds to the $\mathrm{SOH} \cdots \mathrm{O} \mathrm{H}$-bond, and index 2 to the $\mathrm{OH} \cdots \mathrm{S}=\mathrm{O} \mathrm{H}$-bond. The $\mathrm{H}$ transfer ratio corresponds to the $\mathrm{S}-\mathrm{OH} \cdots \mathrm{O} \mathrm{H}$-bond and is defined above. For details, see the text, Figure 1 and refs 34 and $35 .{ }^{b}$ Without counterpoise corrections. ${ }^{c}$ With counterpoise corrections ${ }^{d}$ Reference 40.

TABLE 6: Intermolecular Distances Related to Hydrogen Bonding and Topological Parameters at the Corresponding Bond Critical Points for the $\mathrm{H}_{2} \mathrm{SO}_{4} \cdot \mathrm{NH}_{3}$ Cluster, Using Different Methods and Basis Sets, with and without Counterpoise Corrections to the Energy and Geometry ${ }^{a}$

\begin{tabular}{|c|c|c|c|c|c|c|c|c|c|}
\hline $\begin{array}{l}\text { method/ } \\
\text { basis set }\end{array}$ & $\begin{array}{l}r_{1} / \\
\AA\end{array}$ & $\begin{array}{c}\rho_{1} / \\
100 \mathrm{au}\end{array}$ & $\begin{array}{c}\nabla^{2} \rho_{1} / \\
100 \mathrm{au}\end{array}$ & $\begin{array}{c}E_{1} / \\
\mathrm{au}\end{array}$ & $\begin{array}{c}r_{2} l \\
\AA\end{array}$ & $\begin{array}{c}\rho_{2} / \\
100 \mathrm{au}\end{array}$ & $\begin{array}{c}\nabla^{2} \rho_{2} / \\
100 \mathrm{au}\end{array}$ & $\begin{array}{c}E_{2} / \\
\text { au }\end{array}$ & $\begin{array}{l}\text { H-tranfer } \\
\text { ratio }\end{array}$ \\
\hline B3LYP/ & $1.556^{b}$ & 7.875 & 6.615 & -2.863 & $2.566^{b}$ & $0.826^{d}$ & $3.596^{d}$ & $0.210^{d}$ & 0.299 \\
\hline D95++(d,p) & $1.578^{c}$ & & & & $2.656^{c}$ & & & & \\
\hline B3LYP/ & $1.593^{b}$ & 7.047 & 6.968 & -2.250 & $2.574^{b}$ & & & & 0.247 \\
\hline $6-311++G(2 d, 2 p)$ & $1.606^{c}$ & & & & $2.597^{c}$ & & & & \\
\hline B3LYP/ & $1.601^{b}$ & 7.148 & 3.598 & -3.000 & $2.525^{b}$ & $0.923^{d}$ & $3.741^{d}$ & $0.179^{d}$ & 0.250 \\
\hline$c c-p V(T+d) Z$ & $1.620^{c}$ & & & & $2.573^{c}$ & & & & \\
\hline B3LYP/ & $1.595^{b}$ & 7.280 & 3.562 & -3.065 & $2.580^{b}$ & & & & 0.258 \\
\hline aug-cc-pV(T+d)Z & $1.598^{b}$ & & & & $2.591^{c}$ & & & & \\
\hline PW91/ & $1.475^{b}$ & 9.828 & 1.762 & -4.684 & $2.447^{b}$ & $1.003^{e}$ & $4.380^{e}$ & $0.254^{e}$ & 0.415 \\
\hline $\mathrm{D} 95++(\mathrm{d}, \mathrm{p})$ & $1.499^{c}$ & & & & $2.457^{c}$ & & & & \\
\hline PW91/ & $1.499^{b}$ & 9.108 & 2.833 & -3.971 & $2.418^{b}$ & $1.147^{e}$ & $4.097^{e}$ & $0.140^{e}$ & 0.360 \\
\hline $6-311++G(2 d, 2 p)$ & $1.511^{c}$ & & & & $2.447^{c}$ & & & & \\
\hline PW91/ & $1.517^{b}$ & 8.938 & -0.110 & -4.484 & $2.382^{b}$ & $1.167^{e}$ & $4.612^{e}$ & $0.232^{e}$ & 0.347 \\
\hline$c c-p V(T+d) Z$ & $1.540^{c}$ & & & & $2.405^{c}$ & & & & \\
\hline PW91/ & $1.503^{b}$ & 9.254 & -0.680 & -4.724 & $2.427^{b}$ & $1.094^{d}$ & $4.341^{d}$ & $0.212^{d}$ & 0.367 \\
\hline aug-cc-pV(T+d)Z & $1.503^{c}$ & & & & $2.434^{c}$ & & & & \\
\hline $\mathrm{MP} 2 /$ & $1.567^{b}$ & 7.001 & 9.376 & -2.337 & $2.555^{b}$ & $0.864^{d}$ & $3.937^{d}$ & $0.212^{d}$ & 0.259 \\
\hline $\mathrm{D} 95++(\mathrm{d}, \mathrm{p})$ & $1.654^{c}$ & & & & $2.637^{c}$ & & & & \\
\hline $\mathrm{MP} 2 /$ & $1.605^{b}$ & 6.437 & 9.796 & -1.806 & $2.488^{b}$ & $0.999^{d}$ & $3.995^{d}$ & $0.134^{d}$ & 0.224 \\
\hline $6-311++G(2 d, 2 p)$ & $1.653^{c}$ & & & & $2.565^{c}$ & & & & \\
\hline MP2/ & $1.579^{b}$ & 7.128 & 5.760 & -3.052 & $2.422^{b}$ & $1.055^{d}$ & $4.728^{d}$ & $0.238^{d}$ & 0.255 \\
\hline$c c-p V(T+d) Z$ & $1.629^{c}$ & & & & $2.512^{c}$ & & & & \\
\hline $\mathrm{MP} 2 /$ & $1.559^{b}$ & 7.485 & 5.299 & -3.318 & $2.417^{b}$ & $1.070^{d}$ & $4.807^{d}$ & $0.235^{d}$ & 0.276 \\
\hline aug-cc-pV(T+d)Z & $1.591^{c}$ & & & & $2.468^{c}$ & & & & \\
\hline
\end{tabular}

${ }^{a} r_{n}$ is the H-bond length, $\rho_{n}$ is the electron density, $\nabla^{2} \rho_{n}$ is its Laplacian and $E_{n}$ is the total electronic energy computed at the bond critical point corresponding to hydrogen bond $n$. Index 1 corresponds to the $\mathrm{S}-\mathrm{OH} \cdots \mathrm{N}$ interaction, and index 2 to the other intermolecular bond critical point, if present. The $\mathrm{H}$ transfer ratio corresponds to the $\mathrm{S}-\mathrm{OH} \cdots \mathrm{N} \mathrm{H}$-bond and is defined above. For details, see the text, Figure 2 and refs 34 and 35 . ${ }^{b}$ Without counterpoise corrections. ${ }^{c}$ With counterpoise corrections. ${ }^{d}$ Corresponds to a $\mathrm{N} \cdots \mathrm{O}=\mathrm{S}$ bond path. ${ }^{e} \mathrm{Corresponds}$ to a $\mathrm{N}-\mathrm{H} \cdots \mathrm{O}=\mathrm{S}$ bond path.

bond path is absent in the computations with low BSSE values, and present in those with high BSSE values. This is not very surprising; after all, the "artificial" orbital overlap caused by basis set superposition might well be manifested as an anomalous- looking bond path. However, the presence of the anomalouslooking bond path in the PW91/aug-cc-pV(T+d)Z and MP2/ aug-cc-pV(T+d)Z calculations, both of which have low BSSE values, does not support this hypothesis. Accordingly, a plausible 

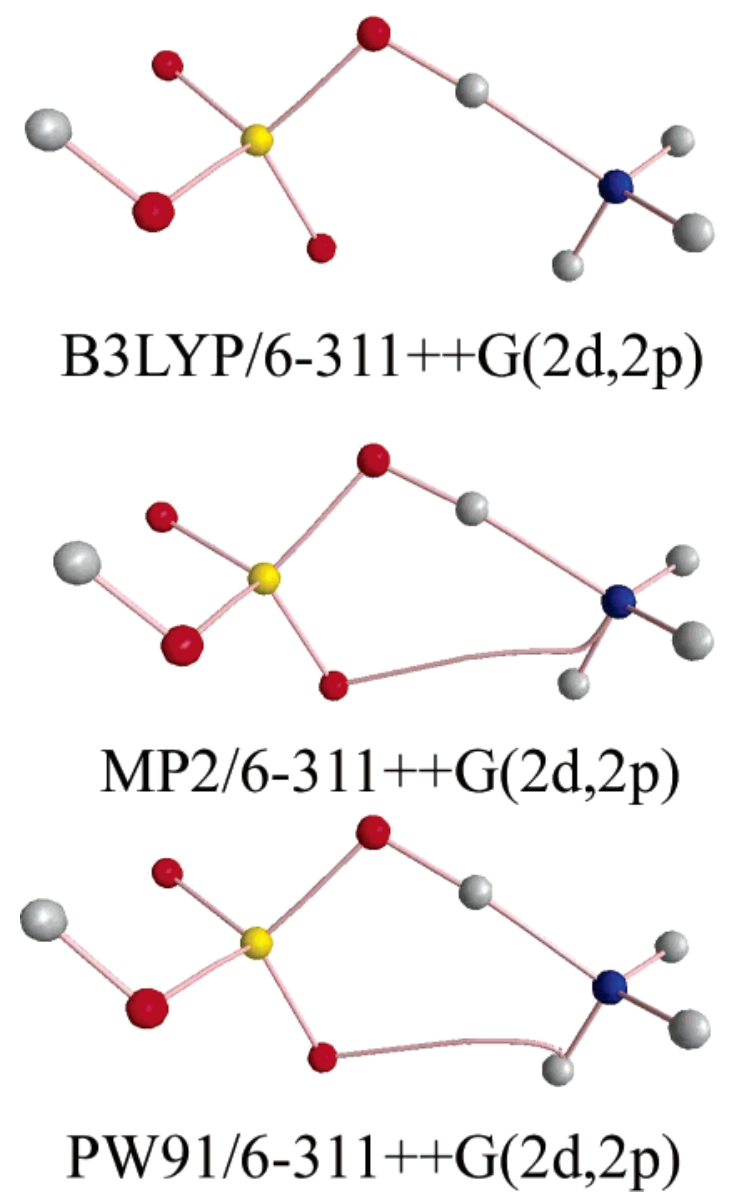

Figure 3. Three different bonding patterns observed for the $\mathrm{H}_{2} \mathrm{SO}_{4}$. $\mathrm{NH}_{3}$ cluster. At the B3LYP/6-311++G(2d,2p) level, only one hydrogen bond is found. At the PW91/6-311++G(2d,2p) level, both a $\mathrm{SOH} \cdots \mathrm{N}$ and a $\mathrm{NH} \cdots \mathrm{O}=\mathrm{S}$ bond are found. At the MP2/6-311++G(2d,2p), a highly curved $\mathrm{N} \cdots \mathrm{O}=\mathrm{S}$ bond path is observed. This figure was created using the AIM2000 program. ${ }^{32}$

explanation is that there is an interaction between the oxygen atom and the $\mathrm{N}-\mathrm{H}$ antibonding molecular orbital. Unfortunately, further analysis of the bonding interactions was hindered by the fact that the Gaussian 03 program is incapable of writing wave function files containing g-type functions or higher. Thus, for example cc-pV $(\mathrm{Q}+\mathrm{d}) \mathrm{Z}$ or aug-cc-pV $(\mathrm{Q}+\mathrm{d})$ wave functions could not be generated for the $\mathrm{H}_{2} \mathrm{SO}_{4} \cdot \mathrm{NH}_{3}$ cluster. In the future, the connection between basis set superposition and this kind of curved bond path could be tested by generating inherently BSSE-free wave functions using the chemical Hamiltonian approach of Mayer et al. ${ }^{41}$ However, this is beyond the scope of this study.

Proton Transfer Ratios. The hydrogen transfer ratios calculated here help to explain some differences in the structural trends observed in earlier studies of $\mathrm{H}_{2} \mathrm{SO}_{4} \cdot\left(\mathrm{H}_{2} \mathrm{O}\right)_{n}$ and $\mathrm{H}_{2} \mathrm{SO}_{4}$. $\left(\mathrm{NH}_{3}\right) \cdot\left(\mathrm{H}_{2} \mathrm{O}\right)_{\mathrm{n}}$ clusters. For example, Bandy and Ianni ${ }^{4}$ predicted that the most stable configurations of $\mathrm{H}_{2} \mathrm{SO}_{4} \cdot\left(\mathrm{H}_{2} \mathrm{O}\right)_{n}$ are neutral for $n=0-7$, whereas Re et al. ${ }^{5}$ computed the ionic and neutral configurations to be equally stable for $n=4$ and the ionic configurations more stable for $n \geq 5$. Similarly, Ianni and Bandy predicted that the switch from neutral to ionic structures occurs at $n=4$ for $\mathrm{H}_{2} \mathrm{SO}_{4} \cdot\left(\mathrm{NH}_{3}\right) \cdot\left(\mathrm{H}_{2} \mathrm{O}\right)_{n}$ clusters, whereas our recent $\mathrm{B} 3 \mathrm{LYP} / \mathrm{D} 95++(\mathrm{d}, \mathrm{p})$ study $^{30}$ indicates that ionic structures are more stable than neutral ones already for $n=1$. Correspondingly, the proton transfer ratio calculated for both $\mathrm{H}_{2} \mathrm{SO}_{4} \cdot \mathrm{H}_{2} \mathrm{O}$ and $\mathrm{H}_{2} \mathrm{SO}_{4} \cdot \mathrm{NH}_{3}$ with the B3LYP/6-311++G(2d,2p) method used by Bandy and Ianni is smaller than that calculated with
TABLE 7: Thermochemical Parameters (kcal mol-1) for the Hydration of Sulfuric Acid with One and Two Water Molecules, at $298 \mathrm{~K}$ and $1 \mathrm{~atm}$, Using the Harmonic Approximation and Anharmonic Corrections ${ }^{a}$

\begin{tabular}{ccccc}
\hline species & $\Delta$ ZPE & $\Delta H$ & $\Delta S$ & $\Delta G$ \\
\hline $\mathrm{H}_{2} \mathrm{SO}_{4} \cdot \mathrm{H}_{2} \mathrm{O}$ & $2.303^{b}$ & $-11.914^{b}$ & $-29.46^{b}$ & $-3.131^{b}$ \\
& $2.151^{c}$ & $-11.927^{c}$ & $-28.15^{c}$ & $-3.534^{c}$ \\
$\mathrm{H}_{2} \mathrm{SO}_{4} \cdot\left(\mathrm{H}_{2} \mathrm{O}\right)_{2}$ & $4.762^{b}$ & $-23.433^{b}$ & $-60.46^{b}$ & $-5.405^{b}$ \\
& $4.489^{c}$ & $-23.462^{c}$ & $-57.77^{c}$ & $-6.238^{c}$
\end{tabular}

${ }^{a}$ Note that tighter convergence criteria were used than for the values given in Tables 3 and 4 . The definitions of the parameters are the same as in Tables 1-4. ${ }^{b}$ Harmonic frequencies. ${ }^{c}$ Anharmonic frequencies.

the B3LYP/D95++ $(d, p)$ method used by Re et al. and in our study. On the other hand, Larson et al. ${ }^{8}$ predicted a proton transfer for the $\mathrm{H}_{2} \mathrm{SO}_{4} \cdot\left(\mathrm{NH}_{3}\right) \cdot\left(\mathrm{H}_{2} \mathrm{O}\right)$ cluster using the MP2/6$311++\mathrm{G}(\mathrm{d}, \mathrm{p})$ method, even though the MP2 transfer ratios calculated here are consistently lower than the corresponding B3LYP values. It should, however, be noted that Larson et al. calculated only binding energies, not free energies, and that they predicted a proton transfer for the $\mathrm{H}_{2} \mathrm{SO}_{4} \cdot\left(\mathrm{NH}_{3}\right) \cdot\left(\mathrm{H}_{2} \mathrm{O}\right)$ cluster also using the B3LYP/6-311++G(d,p) method. Comparing the results of Bandy and Ianni with those of Larson et al., one can see that a small change in the basis set (in this case, adding a p-type polarization function to each hydrogen atom and a d-type polarization function to all other atoms) can have huge effects on the structural results. This might also indicate that the large differences observed between the $6-311++\mathrm{G}(2 \mathrm{~d}, 2 \mathrm{p})$ basis set and the cc-pV(T+d)Z or aug-cc-pV(T+d)Z sets, all of triple split-valence quality, is related primarily to the presence of f-type polarization functions in the correlation-consistent sets.

Effect of Anharmonic Corrections. We have checked the validity of the harmonic approximation by calculating the anharmonic frequencies and vibrational contributions to the free energy of hydration of sulfuric acid mono- and dihydrate at the B3LYP/cc-pV $(\mathrm{T}+\mathrm{d}) \mathrm{Z}$ level using the anharmonic corrections implemented in the Gaussian 03 program. The relevant thermochemical parameters obtained using harmonic and anharmonic frequencies are given in Table 7.

On the basis of ref 14 , tighter convergence criteria were used for this computation, as mentioned in the section "Computational Details". This affected the optimized bond lengths by less than $0.001 \AA$ A A comparison of Tables 7 and 3 shows that for example the free energy of hydration of sulfuric acid changes by about $0.06 \mathrm{kcal} \mathrm{mol}^{-1}$ when tighter convergence criteria and the ultrafine integration grid are used instead of the default settings. However, given the magnitudes of the other error sources revealed by this study, it is clearly not cost-effective to routinely use convergence and grid settings much tighter than the default ones.

The anharmonic frequencies computed using the Gaussian 03 program are in reasonable agreement with those computed recently by Miller et al. ${ }^{42}$ using the GAMESS package and the CC-VSCF method at the MP2/TZP level. The sum of the differences between the nine experimentally observed vibrational wavenumbers ${ }^{43}$ and the corresponding computed wavenumbers is $219 \mathrm{~cm}^{-1}$ for our results and $104 \mathrm{~cm}^{-1}$ for those of Miller et al. This is probably due to the higher accuracy of the CC-VSCF and MP2 methods. However, for the purposes of thermochemical analysis, also our anharmonic computations are a significant improvement over the harmonic approximation.

It can be seen from Table 7 that the effect of anharmonic corrections is far from insignificant. The absolute values of the reaction free energies, for example, increase by ca. $15 \%$ when anharmonicity is accounted for. However, compared to the errors 
TABLE 8: Ratio of Anharmonic to Harmonic Zero-Point Energies for Four Different Molecular Structures

\begin{tabular}{lllll}
\hline species & $\mathrm{H}_{2} \mathrm{SO}_{4} \cdot\left(\mathrm{H}_{2} \mathrm{O}\right)_{2}$ & $\mathrm{H}_{2} \mathrm{SO}_{4} \cdot \mathrm{H}_{2} \mathrm{O}$ & $\mathrm{H}_{2} \mathrm{SO}_{4}$ & $\mathrm{H}_{2} \mathrm{O}$ \\
$\mathrm{ZPE}_{\text {anharm }} / \mathrm{ZPE}_{\text {harm }}$ & 0.98122 & 0.98209 & 0.98542 & 0.98426
\end{tabular}

caused by basis-set superposition and to the differences in results obtained at different method/basis set combinations, the errors caused by the harmonic approximation are relatively small.

One possibility is to account for anharmonicity through the use of scaling factors, which can be applied directly to either the vibrational frequencies or the zero-point energies and thermal vibrational contributions. When the use of scaling factors is considered, it should be noted that the "anharmonicity" (defined, e.g., as the ratio of anharmonic and harmonic vibrational frequencies or zero-point energies) is different for clusters and for isolated molecules. Intramolecular bonds are usually rigid, and thus close to harmonic, whereas intermolecular bonds may display significant anharmonicity. This is illustrated by Table 8 , in which the ratio of anharmonic to harmonic zero-point energies of the four species studied are compared.

Thus, using the same scaling factor both for isolated molecules and for cluster structures will inevitably lead to errors, which may be of the same order of magnitude as the original error caused by the harmonic approximation. It might be possible to attain greater accuracy by using different scaling factors for frequencies corresponding to intra- and intermolecular vibrations, but such an approach is beyond the scope of this study.

It should be noted that the large anharmonicity of the intermolecular bonds leads to a significant deviation of the vibrationally averaged geometry from the optimized minimum energy geometry. For the $\mathrm{H}_{2} \mathrm{SO}_{4} \cdot \mathrm{H}_{2} \mathrm{O}$ cluster, the vibrationally averaged anharmonic zero-point $\mathrm{SOH} \cdots \mathrm{O} \mathrm{H}$-bond length was greater by $0.005 \AA$ and the $\mathrm{OH} \cdots \mathrm{O}=\mathrm{S}$ H-bond greater by 0.104 $\AA$ than the minimum energy bond length. This makes the large difference between the calculated minimum-energy bond lengths in Table 5 and the experimental values by Fiacco et al. ${ }^{40}$ even more surprising, as the experimental values correspond to the vibrationally averaged structure and could therefore be expected to be larger, not smaller, than the calculated ones.

Higher-Level Computations. As mentioned above, the ZPE and thermal contributions to the reaction free energies vary relatively little between different methods, whereas the differences in electronic energies are significant. Thus, it might be feasible to compute the minimum geometry and thermochemical parameters using a lower level of theory and the electronic energy at a higher level. Several such schemes exist, e.g., the G1 and G2 methods. ${ }^{44}$ However, these do not account explicitly for basis set superposition (which we have found to be significant even for relatively large basis sets), and often employ configuration interaction methods, which are not size consistent. As future atmospheric ab initio studies will certainly include comparing properties of clusters of varying size, this is clearly undesirable. Furthermore, most such schemes use constant scaling factors to account for anharmonicity, which is not a very good approach for cluster structures, as discussed in the previous section.

We have chosen to calculate the single-point binding energy of $\mathrm{H}_{2} \mathrm{SO}_{4} \cdot \mathrm{H}_{2} \mathrm{O}$ using the $\mathrm{CCSD}(\mathrm{T})$ method, which is both sizeconsistent and known to give very accurate results. ${ }^{45}$ Because it is counterproductive to employ high-level correlated theories with less than triple-valence basis sets, ${ }^{45}$ we have used the cc$\mathrm{pV}(\mathrm{T}+\mathrm{d}) \mathrm{Z}$ basis set for these calculations. Due to computational considerations (and also due to the fact that there are no direct experimental results to compare with) the $\mathrm{H}_{2} \mathrm{SO}_{4} \cdot \mathrm{NH}_{3}$ cluster was not studied at the $\operatorname{CCSD}(\mathrm{T})$ level.
TABLE 9: Binding Energies (kcal mol ${ }^{-1}$ ) of $\mathrm{H}_{2} \mathrm{SO}_{4} \cdot \mathrm{H}_{2} \mathrm{O}$ Calculated at the CCSD(T) - Level, Including Counterpoise Corrections (CP), with Geometries Optimized at Lower Levels of Theory ${ }^{a}$

\begin{tabular}{|c|c|c|c|c|}
\hline $\begin{array}{l}\text { method of geometry } \\
\text { optimization }\end{array}$ & $\Delta E_{0, \mathrm{CCSD}(\mathrm{T})}$ & $\begin{array}{c}\Delta E_{0, \mathrm{CCSD}(\mathrm{T})}- \\
\Delta E_{0, \mathrm{X}}\end{array}$ & $\begin{array}{c}\mathrm{CP} \\
\text { correction }\end{array}$ & $\begin{array}{c}\Delta G_{\mathrm{X}}+ \\
\Delta E_{0, \mathrm{CCSD}(\mathrm{T})}- \\
\Delta E_{0, \mathrm{X}}\end{array}$ \\
\hline B3LYP/cc-pV $(T+d) Z$ & -11.439 & 0.039 & 2.530 & -1.105 \\
\hline PW91/cc-pV(T+d)Z & -11.088 & 1.899 & 2.482 & -0.623 \\
\hline MP2/cc-pV(T+d)Z & -11.470 & 0.199 & 2.858 & -1.200 \\
\hline B3LYP/cc-pV(D+d)Z & -9.930 & -1.964 & 6.046 & \\
\hline
\end{tabular}

${ }^{a}$ The $\operatorname{CCSD}(\mathrm{T})$ calculations use the same basis set as the corresponding lower-level calculations. $-\Delta E_{0, \mathrm{X}}$ is the (counterpoise-corrected) binding energy calculated at the corresponding lower level of theory. The value of $\Delta G_{\mathrm{X}}+\Delta E_{0, \mathrm{CCSD}(\mathrm{T})}-\Delta E_{0, \mathrm{X}}$ corresponds to Gibbs free energy obtained by calculating the electronic energy at the $\operatorname{CCSD}(\mathrm{T})$ level and the zero-point and thermal contributions at the lower level of theory.

As the optimum geometries obtained using different methods are somewhat different (see Tables 5 and 6), we have run a $\operatorname{CCSD}(\mathrm{T})$ calculation at the (counterpoise-corrected) optimum geometry corresponding to each of the three lower-level calculations: B3LYP/cc-pV(T+d)Z, PW91/cc-pV(T+d)Z and $\mathrm{MP} 2 / \mathrm{cc}-\mathrm{pV}(\mathrm{T}+\mathrm{d}) \mathrm{Z}$. The energies of the free sulfuric acid and water molecules were also calculated at the optimum geometries corresponding to these methods, as relaxing the reactants but not the product at the $\operatorname{CCSD}(\mathrm{T})$ level would lead to an artificially low binding energy. (A full geometry optimization of $\mathrm{H}_{2} \mathrm{SO}_{4}$. $\mathrm{H}_{2} \mathrm{O}$ at the $\operatorname{CCSD}(\mathrm{T})$ level, on the other hand, would be prohibitively expensive.) Counterpoise corrections to the electronic energy were included in the $\operatorname{CCSD}(\mathrm{T})$ calculations to remove the basis set superposition error. For comparison, we have also calculated the $\operatorname{CCSD}(\mathrm{T})$ binding energy using the cc$\mathrm{pV}(\mathrm{D}+\mathrm{d}) \mathrm{Z}$ basis set, at the B3LYP/cc-pV $(\mathrm{D}+\mathrm{d}) \mathrm{Z}$ geometry. The results are presented in Table 9.

It can be seen from Table 9 that the $\operatorname{CCSD}(\mathrm{T}) / \mathrm{cc}-\mathrm{pV}(\mathrm{T}+\mathrm{d}) \mathrm{Z}$ electronic energies calculated at the B3LYP and MP2 minimum geometries differ a little from the corresponding B3LYP and MP2 energies, whereas the $\operatorname{CCSD}(\mathrm{T})$ binding energy calculated at the PW91 geometry is significantly lower than the original PW91 value. This indicates (though unfortunately does not prove) that the PW91/cc-pV(T+d)Z potential energy surface is overbinding compared to the $\operatorname{CCSD}(\mathrm{T}) / \mathrm{cc}-\mathrm{pV}(\mathrm{T}+\mathrm{d}) \mathrm{Z}$ surface, whereas the B3LYP/cc-pV $(\mathrm{T}+\mathrm{d}) \mathrm{Z}$ and MP2/cc-pV $(\mathrm{T}+\mathrm{d}) \mathrm{Z}$ are quite close to it. Because the $\operatorname{CCSD}(\mathrm{T})$ results are almost certainly more accurate than any of the other methods, it would thus be reasonable to conclude that the B3LYP and MP2 reaction energies and geometries should be considered more reliable than the PW91 ones. (This conclusion is also supported by the fact that the B3LYP and MP2 results are, when larger basis sets are used, very similar to each other.) However, the fact remains that both the PW91 reaction energies and the corresponding $\mathrm{H}$-bond lengths are closer to the experimental values. A full resolution of the problem would probably require a geometry optimization at the $\operatorname{CCSD}(\mathrm{T}) /$ aug-cc-pV $(\mathrm{T}+\mathrm{d}) \mathrm{Z}$ level or higher, which is computationally unfeasible at the moment.

We have also attempted to calculate the basis-set limits of the binding energies of $\mathrm{H}_{2} \mathrm{SO}_{4} \cdot \mathrm{H}_{2} \mathrm{O}$ and $\mathrm{H}_{2} \mathrm{SO}_{4} \cdot \mathrm{NH}_{3}$ at the B3LYP level. This was done by calculating the counterpoisecorrected binding energies using the cc-pV(D+d)Z, cc-pV$(\mathrm{T}+\mathrm{d}) \mathrm{Z}, \mathrm{cc}-\mathrm{pV}(\mathrm{Q}+\mathrm{d}) \mathrm{Z}$, aug-cc-pV $(\mathrm{D}+\mathrm{d}) \mathrm{Z}$, aug-cc-pV $(\mathrm{T}+\mathrm{d}) \mathrm{Z}$ and aug-cc-pV( $\mathrm{Q}+\mathrm{d}) \mathrm{Z}$ basis sets. (Due to computational limitations, the aug-cc-pV(Q+d)Z energy was computed at the augcc-pV(T+d)Z geometry.) The basis-set limits could then be estimated using the extrapolation formulas ${ }^{46,47}$ 


$$
E(X)=E(\infty)+A_{1} \mathrm{e}^{-B X}
$$

and

$$
E(X)=E(\infty)+A_{2} X^{-3}
$$

where $E(\infty)$ is the basis-set limit energy, $A_{1}, A_{2}$ and $B$ are constants, $X=2$ for the cc-pV(D+d) and aug-cc-pV(D+d)Z sets, $X=3$ for the cc-pV(T+d) and aug-cc-pV(T+d)Z sets and $X=4$ for the cc-pV $(\mathrm{Q}+\mathrm{d})$ and aug-cc-pV $(\mathrm{Q}+\mathrm{d}) \mathrm{Z}$ sets. For the total electronic energy, eq 1 holds for Hartree-Fock methods and eq 2 for correlated ab initio methods. ${ }^{45}$ Though not rigorously proven, both formulas have been successfully employed for many other molecular properties, and also for DFT methods. (See for example ref 27, where both formulas are applied to B3LYP results.) Equations 1 and 2 were fitted separately to the data corresponding to the augmented and nonaugmented basis sets. Though eqs 1 and 2 are usually fitted to uncorrected energies, we have followed the recommendations in ref 48 and used the counterpoise-corrected energies for the fitting, though this led to nonmonotonic behavior for the augmented basis set energies. (However, because the differences between the aug-cc-pV $(\mathrm{T}+\mathrm{d})$ and aug-cc-pV $(\mathrm{Q}+\mathrm{d})$ energies were very small, this had a negligible effect on the results.) Equation 2 was also fitted using only the $X=3$ and $X=4$ data points, on the basis of recommendations from ref 49. Furthermore, we have attempted to estimate the magnitude of basisset effects beyond the triple- $\zeta$ level for the $\operatorname{CCSD}(\mathrm{T})$ method by calculating the $\operatorname{CCSD}(\mathrm{T}) / \mathrm{cc}-\mathrm{pV}(\infty+\mathrm{d}) \mathrm{Z}$ binding energy using eq 2 and the two data points corresponding to the B3LYP geometries given in Table 9. (This value must be considered as an order-of-magnitude estimate only, as the very large BSSE error indicates that the $\operatorname{CCSD}(\mathrm{T}) / \mathrm{cc}-\mathrm{pV}(\mathrm{D}+\mathrm{d}) \mathrm{Z}$ results are quite unreliable.) For comparison, the $\operatorname{CCSD}(\mathrm{T}) / \mathrm{cc}-\mathrm{pV}(\infty+\mathrm{d}) \mathrm{Z}$ energy has been calculated both with and without counterpoise corrections. The results are presented in Table 10.

The counterpoise-corrected quadruple- $\zeta$ energies are very close to the B3LYP basis set limit, irrespective of the extrapolation formula used. However, it should be noted that without counterpoise corrections, the difference between the cc-pV$(\mathrm{Q}+\mathrm{d}) \mathrm{Z}$ and $\mathrm{cc}-\mathrm{pV}(\infty+\mathrm{d}) \mathrm{Z}$ energies is around $1 \mathrm{kcal} \mathrm{mol}^{-1}$. The augmented basis sets, on the other hand, converge much faster, and the effect of the counterpoise correction at the augcc-pV $(\mathrm{Q}+\mathrm{d}) \mathrm{Z}$ level is smaller than the differences between the different extrapolation procedures. Even the counterpoisecorrected aug-cc-pV(D+d)Z energies are within $0.5 \mathrm{kcal} \mathrm{mol}^{-1}$ of the basis-set limit energies. This indicates that the aug-cc$\mathrm{pV}(\mathrm{D}+\mathrm{d}) \mathrm{Z}$ basis set might represent a reasonable compromise between computational requirements and accuracy.

It can be seen from Table 10 that the "basis-set limit correction" to the $\mathrm{B} 3 \mathrm{LYP} / \mathrm{cc}-\mathrm{pV}(\mathrm{T}+\mathrm{d}) \mathrm{Z}$ electronic energy change of the $\mathrm{H}_{2} \mathrm{SO}_{4}+\mathrm{H}_{2} \mathrm{O} \leftrightarrow \mathrm{H}_{2} \mathrm{SO}_{4} \cdot \mathrm{H}_{2} \mathrm{O}$ reaction is ca. +0.25 to $+0.5 \mathrm{kcal} \mathrm{mol}^{-1}$. The correction thus acts to further increase the difference between computational and experimental results. This could be taken as an indication that the counterpoise correction overcompensates for the basis-set superposition error and leads to artificially low binding energies. The magnitude of this possible overcompensation can be estimated by comparing the basis-set limit energies calculated from data with and without counterpoise corrections. If no overcompensation is present, the values should be identical. For the augmented basis sets, the difference between the two results (using eq 2 and the full data set) is less than $0.1 \mathrm{kcal} \mathrm{mol}^{-1}$ for both clusters studied, indicating (though not proving) that the degree of overcom-
TABLE 10: Basis-Set Limit Binding Energies of $\mathrm{H}_{2} \mathrm{SO}_{4} \cdot \mathrm{H}_{2} \mathrm{O}$ and $\mathrm{H}_{2} \mathrm{SO}_{4} \cdot \mathrm{NH}_{3}$ Calculated at the B3LYP Level and Basis-Set Limit Binding Energies of $\mathrm{H}_{2} \mathrm{SO}_{4} \cdot \mathrm{H}_{2} \mathrm{O}$ at the

\begin{tabular}{|c|c|c|c|c|}
\hline \multirow[b]{2}{*}{ method/basis set } & \multicolumn{2}{|c|}{$\mathrm{H}_{2} \mathrm{SO}_{4} \cdot \mathrm{H}_{2} \mathrm{O}$} & \multicolumn{2}{|c|}{$\mathrm{H}_{2} \mathrm{SO}_{4} \cdot \mathrm{NH}_{3}$} \\
\hline & $\Delta E_{0}$ & $\begin{array}{c}\mathrm{CP} \\
\text { correction }\end{array}$ & $\Delta E_{0}$ & $\begin{array}{c}\mathrm{CP} \\
\text { correction }\end{array}$ \\
\hline B3LYP/cc-pV(D+d)Z & -11.894 & 5.577 & -15.166 & 4.618 \\
\hline B3LYP/cc-pV(T+d)Z & -11.477 & 1.997 & -14.809 & 1.871 \\
\hline B3LYP/cc-pV(Q+d)Z & -11.243 & 0.914 & -14.768 & 0.835 \\
\hline B3LYP/cc-pV( $\infty+d) Z$, eq 1 & -10.941 & & -14.763 & \\
\hline B3LYP/cc-pV $(\infty+d) Z$, eq $2^{a}$ & -11.206 & & -14.692 & \\
\hline B3LYP/cc-pV( $(\infty+d) Z$, eq $2^{b}$ & -11.072 & & -14.739 & \\
\hline B3LYP/aug-cc-pV(D+d)Z & -10.659 & 0.525 & -14.485 & 0.797 \\
\hline B3LYP/aug-cc-pV(T+d)Z & -11.001 & 0.157 & -14.767 & 0.154 \\
\hline B3LYP/aug-cc-pV(Q+d) $Z^{c}$ & -11.027 & 0.090 & -14.747 & 0.085 \\
\hline B3LYP/aug-cc-pV( $\infty+d) Z$, eq 1 & -11.029 & & -14.757 & \\
\hline B3LYP/aug-cc-pV $(\infty+d) Z$, eq $2^{a}$ & -11.104 & & -14.822 & \\
\hline B3LYP/aug-cc-pV( $\infty+d) Z$, eq $2^{b}$ & -11.046 & & -14.733 & \\
\hline $\operatorname{CCSD}(\mathrm{T}) / \mathrm{cc}-\mathrm{pV}(\infty+\mathrm{d}) \mathrm{Z}$, eq $2, \mathrm{CP}^{d}$ & -12.074 & & & \\
\hline
\end{tabular}
CCSD(T) Level (kcal mol-1)

cc-pV $(\infty+\mathrm{d}) \mathrm{Z}$, eq 2 , no $\mathrm{CP}^{e}-13.123$

${ }^{a}$ Fitted using all data points. ${ }^{b}$ Fitted using the $X=3$ and $X=4$ data points only. ${ }^{c}$ Computed at the aug-cc-pV(T+d)Z geometry. ${ }^{d}$ Computed at the corresponding B3LYP geometries, using the counterpoise-corrected $X=2$ and $X=3$ data given in Table 9. ${ }^{e}$ Computed at the corresponding B3LYP geometries, using the $X=2$ and $X=3$ data given in Table 9, without counterpoise corrections.

pensation at the B3LYP level is small. For the nonaugmented basis sets, the counterpoise-uncorrected basis-set limit binding energies are around $0.4 \mathrm{kcal} \mathrm{mol}^{-1}$ higher than the counterpoisecorrected ones, indicating the possible presence of some degree of overcompensation, though not enough to explain the difference between experimental and calculated B3LYP energies. (It should be noted that the differences may also be caused by the incompleteness of our data set, which includes only double-, triple-, and quadruple- $\zeta$ basis sets.)

Comparing the $\operatorname{CCSD}(\mathrm{T}) / \mathrm{cc}-\mathrm{pV}(\infty+\mathrm{d}) \mathrm{Z}$ values given in Table 10 to the corresponding cc-pV(D+d)Z and cc-pV(T+d)Z values in Table 9, one can see that the $\operatorname{CCSD}(\mathrm{T}) / \mathrm{cc}-\mathrm{pV}(\mathrm{T}+\mathrm{d}) \mathrm{Z}$ binding energy is significantly lower than the estimated basis-set limit: ca. $0.6 \mathrm{kcal} \mathrm{mol}^{-1}$ for the counterpoise-corrected and $0.8 \mathrm{kcal}$ $\mathrm{mol}^{-1}$ for the uncorrected values. Also, the difference between the basis-set limit binding energies calculated from counterpoisecorrected and uncorrected energies is over $1 \mathrm{kcal} \mathrm{mol}^{-1}$, indicating that overcompensation may be an important factor at the $\operatorname{CCSD}(\mathrm{T})$ level.

The fitted $\operatorname{CCSD}(\mathrm{T}) / \mathrm{cc}-\mathrm{pV}(\infty+\mathrm{d}) \mathrm{Z}$ values, though not quantitatively accurate due to the unreliability of the $\operatorname{CCSD}(\mathrm{T}) / \mathrm{cc}$ $\mathrm{pV}(\mathrm{D}+\mathrm{d}) \mathrm{Z}$ data, strongly indicate that the B3LYP binding energies are too low by about $1-2 \mathrm{kcal} \mathrm{mol}^{-1}$ (depending on whether the counterpoise-corrected or uncorrected CCSD(T) data is used for comparison). This is almost certainly the main reason for the large differences between earlier studies and experimental values. From Table 7, we can estimate the magnitude of anharmonic corrections to the hydration free energy to be around $-0.4 \mathrm{kcal} \mathrm{mol}^{-1}$. Combining the free energy of hydration calculated at the B3LYP/cc-pV(T+d)Z level with this anharmonic correction and the difference between the B3LYP/cc-pV $(\infty+d) Z$ and $\operatorname{CCSD}(\mathrm{T}) / \mathrm{cc}-\mathrm{pV}(\infty+\mathrm{d}) \mathrm{Z}$ binding energies, we obtain a range of -2.2 to $-2.9 \mathrm{kcal} \mathrm{mol}^{-1}$ as a "best-guess" value of the free energy of hydration at $298 \mathrm{~K}$. (The higher value corresponds to counterpoise-corrected and the lower value to uncorrected basis-set limit energies.) This is in moderately good agreement with the upper limit of the experimental range of $-3.6 \pm 1 \mathrm{kcal} \mathrm{mol}^{-1}$. Further calculations at the $\operatorname{CCSD}(\mathrm{T}) / \mathrm{aug}-\mathrm{cc}-\mathrm{pV}(\mathrm{T}+\mathrm{d}) \mathrm{Z}$ or $\operatorname{CCSD}(\mathrm{T}) / \mathrm{cc}-\mathrm{pV}(\mathrm{Q}+\mathrm{d}) \mathrm{Z}$ level would be required to better determine the magnitude of 
the possible overcompensation of the counterpoise correction to the $\operatorname{CCSD}(\mathrm{T})$ energies, and thus narrow down the range of our "best-guess" value, but the computational cost of such calculations would be formidable.

The above analysis demonstrates that the discrepancy between experimental and theoretical results can be resolved by a combination of anharmonic corrections to the vibrational frequencies and very high-level corrections to the electronic energies. Although satisfactory in itself, this is not very useful for future studies on larger clusters, for which $\operatorname{CCSD}(\mathrm{T})$ calculations with triple- or quadruple- $\zeta$ quality basis sets will remain impossible for the foreseeable future. It is noteworthy that explaining the differences between calculated and experimental values required the estimation of basis-set effects beyond the $\operatorname{CCSD}(\mathrm{T}) / \mathrm{cc}-\mathrm{pV}(\mathrm{T}+\mathrm{d}) \mathrm{Z}$ level, as not even the computationally demanding single-point $\operatorname{CCSD}(\mathrm{T}) / \mathrm{cc}-\mathrm{pV}(\mathrm{T}+\mathrm{d}) \mathrm{Z}$ calculations given in Table 10 were by themselves able to resolve the observed discrepancies. Clearly, future studies on larger clusters will require a more accurate but at the same time computationally feasible method for the calculation of electronic energies. Though some authors believe that the PW91 functional fulfills this requirement, the overbinding of $1.9 \mathrm{kcal} \mathrm{mol}^{-1}$ observed in Table 9 indicates that this is not the case. (It should be noted that this value cannot be explained by overcompensation of the $\mathrm{CP}$ correction at the $\operatorname{CCSD}(\mathrm{T})$ level, as the magnitude of this effect is at most $1 \mathrm{kcal} \mathrm{mol}^{-1}$, as described above.) We are optimistic that the new generation of density functionals being developed especially for nonbonding interactions (see, e.g., ref 50 for some examples) will be suitable for the task.

\section{Conclusions}

We have carried out a systematic analysis of the dependence of the thermochemical and structural parameters of sulfuric acid hydrate and ammonium hydrogensulfate obtained from ab initio and density functional theory calculations on the method and basis set used. We have also estimated the magnitude of the errors caused by basis set superposition and the use of the harmonic approximation for molecular vibrations. We found that the intermolecular bond lengths and binding energies are highly dependent on the method and basis set used, and that the basis set superposition error (BSSE) is very significant even for quite large basis sets of triple or even quadruple-valence quality, unless additional diffuse basis functions are used, as in the aug$c c-p V(X+d) Z$ sets. Comparisons of different basis sets also indicate that including additional polarization functions of high angular momentum quantum number in the basis sets also has a large effect on the structural and energetic results. Different magnitudes of BSSE for different methods/basis set combinations explain part of the differences between earlier studies. The vibrational contributions to the thermochemical parameters were found to be relatively insensitive to the method, basis set and counterpoise corrections. The effect of anharmonic corrections to the vibrational zero-point energies and the thermal vibrational contributions to the reaction free energy were found to be small but not insignificant.

QTAIM analysis reveals qualitative differences between computations on ammonium hydrogensulfate carried out using different methods/basis sets. Most method/basis set combinations associated with large BSSE values display a curved bond path, which is absent in computations associated with lower BSSE values. However, this correlation is not perfect, as the aug-cc$\mathrm{pV}(\mathrm{T}+\mathrm{d}) \mathrm{Z}$ results display both low BSSE values and curved bond paths. In the absence of a generally available method to generate BSSE-free wave functions, the connection between basis set superposition and curved bond paths could not be explored fully. However, we may assume that there could be an interaction between oxygen and the $\mathrm{N}-\mathrm{H}$ antibonding orbital. We have also used QTAIM analysis to define a proton transfer ratio parameter, which helps explain differences in structural features observed in earlier studies.

On the basis of our calculations, we recommend that future ab initio computations on atmospherically relevant clusters should correct for the basis set superposition error at least with respect to the electronic energy, even when large basis sets are used. Vibrational contributions to the relevant thermochemical parameters can be computed at computationally cheaper levels and small or medium-sized basis sets without great loss of accuracy. Higher-level calculations and complete basis-set limit fits at the B3LYP and CCSD(T) levels strongly indicate that the difference between the experimental and most reliable previous theoretical values for the hydration free energies of the $\mathrm{H}_{2} \mathrm{SO}_{4} \cdot \mathrm{H}_{2} \mathrm{O}$ cluster are caused by the inaccuracy of the B3LYP electronic energies. A combination of anharmonic and $\operatorname{CCSD}(\mathrm{T})-$ level corrections yields a range of -2.2 to -2.9 $\mathrm{kcal} \mathrm{mol}^{-1}$ for the free energy of hydration at $298 \mathrm{~K}$, depending on whether counterpoise corrections are used in the basis-set limit fits. This is in reasonable agreement with the upper limit of the experimental range of $3.6 \pm 1 \mathrm{kcal} \mathrm{mol}^{-1}$.

Acknowledgment. We thank the Academy of Finland (Grants 211483 and 211484) and the Estonian Science Foundation (Grant 5387) for funding and the CSC-Center for Scientific Computing for the computer time. We also thank Nino Runeberg at CSC and Juha Vaara at the Department of Chemistry of the University of Helsinki for their advice.

\section{References and Notes}

(1) Korhonen, P.; Kulmala, M.; Laaksonen, A.; Viisanen, Y.; McGraw, R.; Seinfeld, J. H. J. Geophys. Res. 1999, 104, 26349.

(2) Anttila, T.; Vehkamäki, H.; Napari, I.; Kulmala, M. Boreal Env. Res. 2005, 10, 511 .

(3) Beichert, P.; Schrems, O. J. Phys. Chem. A 1998, 102, 10540.

(4) Bandy, A. R.; Ianni, J. C. J. Phys. Chem. A 1998, 102, 6533 3535 .

(5) Re, S.; Osamura, Y.; Morokuma, K. J. Phys. Chem. A 1999, 103,

(6) Ding, C-C.; Laasonen, K.; Laaksonen, A. J. Phys. Chem A $\mathbf{2 0 0 3}$ 107, 8648.

(7) Al Natsheh, A.; Nadykto, A. B.; Mikkelsen, K. V.; Yu, F.; Ruuskanen, J. J. Phys. Chem. A 2004, 108, 8914. 786.

(8) Larson, L. J.; Largent, A.; Tao, F-M. J. Phys. Chem. A 1999, 103,

(9) Ianni, J. C.; Bandy, A. R. J. Phys. Chem. A 1999, 103, 2801

(10) Hanson, D. R.; Eisele. F. L. J. Phys. Chem. A 2000, 104, 1715.

(11) Eisele, F. L.; Hanson, D. R. J. Phys. Chem. A 2000, 104, 830.

(12) Boys, S. F.; F. Bernardi, F. Mol. Phys. 1970, 19, 553.

(13) Frisch, M. J.; Trucks, G. W.; Schlegel, H. B.; Scuseria, G. E.; Robb, M. A.; Cheeseman, J. R.; Montgomery, J. A., Jr.; Vreven, T.; Kudin, K. N.; Burant, J. C.; Millam, J. M.; Iyengar, S. S.; Tomasi, J.; Barone, V. Mennucci, B.; Cossi, M.; Scalmani, G.; Rega, N.; Petersson, G. A.; Nakatsuji, H.; Hada, M.; Ehara, M.; Toyota, K.; Fukuda, R.; Hasegawa, J.; Ishida, M.; Nakajima, T.; Honda, Y.; Kitao, O.; Nakai, H.; Klene, M.; Li, X.; Knox, J. E.; Hratchian, H. P.; Cross, J. B.; Bakken, V.; Adamo, C.; Jaramillo, J.; Gomperts, R.; Stratmann, R. E.; Yazyev, O.; Austin, A. J.; Cammi, R.; Pomelli, C.; Ochterski, J. W.; Ayala, P. Y.; Morokuma, K.; Voth, G. A.; Salvador, P.; Dannenberg, J. J.; Zakrzewski, V. G.; Dapprich, S.; Daniels, A. D.; Strain, M. C.; Farkas, O.; Malick, D. K.; Rabuck, A. D.; Raghavachari, K.; Foresman, J. B.; Ortiz, J. V.; Cui, Q.; Baboul, A. G.; Clifford, S.; Cioslowski, J.; Stefanov, B. B.; Liu, G.; Liashenko, A.; Piskorz, P.; Komaromi, I.; Martin, R. L.; Fox, D. J.; Keith, T.; Al-Laham, M. A.; Peng, C. Y.; Nanayakkara, A.; Challacombe, M.; Gill, P. M. W.; Johnson, B.; Chen, W.; Wong, M. W.; Gonzalez, C.; Pople, J. A. Gaussian 03, revision C.02; Gaussian, Inc.: Wallingford, CT, 2004.

(14) Barone, C. J. Chem. Phys. 2005, 122, 014108.

(15) Becke, A. D. J. Chem. Phys. 1993, 98, 5648

(16) Lee, C.; Yang, W.; Parr, R. G. Phys. Rev. B 1988, 37, 785

(17) Perdew, J. P.; Burke, K.; Wang, Y. Phys. Rev. B 1996, 54, 16533

(18) Møller, C.; Plesset, M. S. Phys. Rev. 1934, 46, 618. 
(19) Pople, J. A.; Head-Gordon, M.; Raghavachari, K. J. Chem. Phys. 1987, 87, 5968

(20) Dunning, T. H., Jr.; Hay, P. J. Modern Theoretical Chemistry; Schaefer, H F., III, Ed.; Plenum; New York, 1976; Vol. 3.

(21) Krishnan, R.; Binkley, J. S.; Seeger, R.; Pople, J. A. J. Chem. Phys. 1980, 72,650

(22) McLean, A. D.; Chandler, G. S. J. Chem. Phys. 1980, 72, 5639

(23) Frisch, M. J.; Pople, J. A.; Binkley, J. S. J. Chem. Phys. 1984, 80, 3265 .

(24) Dunning, T. H., Jr.; Peterson, K. A.; Wang, A. K. J. Chem. Phys. 2001, 114, 9244 .

(25) Dunning, T. H., Jr. J. Chem. Phys. 1989, 90, 1007.

(26) Wilson, A. K.; van Mourik, T.; Dunning, T. H., Jr. J. Mol. Struct. 1996, 388,339 .

(27) Wang, N. X.; Wilson, A. K. J. Phys. Chem. A 2003, 107, 6720

(28) Wilson, A.; Dunning, T. H., Jr. J. Phys. Chem. A 2004, 108, 3129.

(29) Vehkamäki, H.; Napari, I.; Kulmala, M.; Noppel, M. Phys. Rev. Lett. 2004, 93, 148501.

(30) Kurtén, T.; Torpo, L.; Ding, C.- G.; Vehkamäki, H.; Sundberg, M. R.; Laasonen, K.; Kulmala, M. Manuscript submitted to J. Phys. Chem. A.

(31) Bader, R. F. W.; Keith, T. A. AIMPAC 95 program package. 1995.

(32) Biegler-König, F.; Schönbom, J. AIM2000 version 2.0. 2002.

(33) Bader, R. F. W. Atoms in Molecules - A Quantum Theory; Oxford University Press; Oxford, 1990.

(34) Bader, R. F. W. J. Phys. Chem. A 1998, 102, 7314

(35) Koch, U.; Popelier, P. L. A. J. Phys. Chem. 1995, 99, 9747.

(36) Rozas, I.; Alkorta, I.; Elguero, J. J. Am. Chem. Soc. 2000, 122, 11154
(37) Flükiger, P.; Lüthi, H. P.; Portmann, S.; Weber, J. MOLEKEL 4.3; Swiss Center for Scientific Computing, Manno (Switzerland), 2000-2002.

(38) Portmann, S.; Lüthi, H. P. Chimia 2000, 54, 766.

(39) Dobado, J. A.; Martinez-Garcia, H.; Molina, J.; Sunberg, M. R. In Advanced Problems and Complex Systems; Quantum Systems in Chemistry and Physics, Vol 2; Hernandez-Laguna, A., et al., Eds.; Kluwer Academic Publishers: London, 2000

(40) Fiacco, D. L.; Hunt, S. W.; Leopold, K. R. J. Am. Chem. Soc. 2002, $124,4504$.

(41) Mayer, I. Mol. Phys. 1997, 92, 503.

(42) Miller, Y.; Chaban, G. M.; Gerber, R. B. J. Phys. Chem. A 2005, 109,6565 .

(43) Givan, A.; Larsen, L. A.; Loewenschuss, A.; Nielsen, C. J. J. Chem. Soc., Faraday Trans. 1998, 94, 827.

(44) Curtiss, L. A.; Raghavachari, K.; Tucks, G. W.; Pople, J. A. J. Chem. Phys. 1993, 98, 1293.

(45) Jensen, F. Introduction to Computational Chemistry; John Wiley \& Sons: New York, 1999.

(46) Helgaker, T.; Klopper, W.; Koch, H.; Noga, J. J. Chem. Phys. 1997, 106, 9639 .

(47) Woon, D. E.; Dunning, T. H., Jr. J. Chem. Phys. 1993, 99, 1914.

(48) Van Mourik, T.; Wilson, A. K.; Peterson, K. A.; Woon, D. E.; Dunning, T. H., Jr. Adv. Quant. Chem. 1998, 31, 105.

(49) Halkier, A.; Helgaker, T.; Jørgensen, P.; Klopper, W.; Koch, H.; Olsen, J.; Wilson, A. K. Chem. Phys. Lett. 1998, 286, 243.

(50) Zhao, Y.; Schultz, N. E.; Truhlar, D. G. J. Chem. Theory Comput. 2006, 2, 364 . 